\title{
Effects of the Incorporation of Distinct Cations in Titanate Nanotubes on the Catalytic Activity in $\mathrm{NO}_{x}$ Conversion
}

\author{
José Vitor C. do Carmo ${ }^{1}$, Cleanio L. Lima ${ }^{2} \oplus$, Gabriela Mota ${ }^{1}$, Ariane M. S. Santos ${ }^{2}$, Ludyane N. Costa ${ }^{2}$, \\ Anupama Ghosh ${ }^{2}$, Bartolomeu C. Viana ${ }^{2}\left(\mathbb{D}\right.$, Monique Silva ${ }^{3}$, João M. Soares ${ }^{4}$, Samuel Tehuacanero-Cuapa ${ }^{5}\left({ }^{(}\right)$, \\ Rossano Lang ${ }^{6}$, Alcineia C. Oliveira ${ }^{1, *}$, Enrique Rodríguez-Castellón ${ }^{7, *} \mathbb{C}$ and Elena Rodríguez-Aguado ${ }^{7}$
}

Citation: Carmo, J.V.C.d.; Lima, C.L. Mota, G.; Santos, A.M.S.; Costa, L.N.; Ghosh, A.; Viana, B.C.; Silva, M.; Soares, J.M.; Tehuacanero-Cuapa, S.; et al. Effects of the Incorporation of Distinct Cations in Titanate Nanotubes on the Catalytic Activity in $\mathrm{NO}_{\mathrm{x}}$ Conversion. Materials 2021, 14, 2181. https://doi.org/10.3390/ ma14092181

Academic Editor: Stefano Lettier

\section{Received: 5 March 2021}

Accepted: 16 April 2021

Published: 24 April 2021

Corrected: 15 February 2022

Publisher's Note: MDPI stays neutral with regard to jurisdictional claims in published maps and institutional affiliations.

Copyright: (c) 2021 by the authors. Licensee MDPI, Basel, Switzerland. This article is an open access article distributed under the terms and conditions of the Creative Commons Attribution (CC BY) license (https:/ / creativecommons.org/licenses/by/ $4.0 /)$.
1 Department of Analytical and Chemical-Physic Chemistry, Pici Campus-Block 940, Federal University of Ceará, Fortaleza 60040-531, Brazil; vitor.costa@alu.ufc.br (J.V.C.d.C.); gabrielamotab@alu.ufc.br (G.M.)

2 Material Science and Engineering \& Physics Department, Federal University of Piauí, Teresina 64049-550, Brazil; cleanio@ufpi.edu.br (C.L.L.); arianeo_1q@bol.com.br (A.M.S.S.); luydiane@bol.com.br (L.N.C.); anupama1984@gmail.com (A.G.); bartolomeu@ufpi.edu.br (B.C.V.)

3 Fortaleza Campus, Federal Institute of Education-IFCE, Av. 13 de Maio, 2081, Benfica, Fortaleza 60040-531, Brazil; moniquessouza22@gmail.com

4 Physics Department, State University of Rio Grande do Norte-UERN, BR 110-km 48, R. Prof. Antônio Campos, Costa e Silva, Mossoró 59610-210, Brazil; joaomsoares@gmail.com

5 Central Microscopy Laboratory, Physics Institute-UNAM, Research Circuit s/n, University City, Coyoacán, Mexico City 04510, Mexico; samueltc@fisica.unam.mx

6 Institute of Science and Technology-ICT, Federal University of São Paulo-UNIFESP, São José dos Campos 12231-280, Brazil; rossano.lang@unifesp.br

7 Department of Inorganic Chemistry, Faculty of Science, University of Málaga, 29071 Málaga, Spain; aguadoelena5@gmail.com

* Correspondence: alcineia@ufc.br (A.C.O.); castellon@uma.es (E.R.-C.)

\begin{abstract}
Effects of the incorporation of $\mathrm{Cr}, \mathrm{Ni}, \mathrm{Co}, \mathrm{Ag}, \mathrm{Al}, \mathrm{Ni}$ and $\mathrm{Pt}$ cations in titanate nanotubes (NTs) were examined on the $\mathrm{NO}_{x}$ conversion. The structural and morphological characterizations evidenced that the ion-exchange reaction of $\mathrm{Cr}, \mathrm{Co}, \mathrm{Ni}$ and $\mathrm{Al}$ ions with the NTs produced catalysts with metals included in the interlayer regions of the trititanate NTs whereas an assembly of Ag and Pt nanoparticles were either on the nanotubes surface or inner diameters through an impregnation process. Understanding the role of the different metal cations intercalated or supported on the nanotubes, the optimal selective catalytic reduction of $\mathrm{NO}_{x}$ by $\mathrm{CO}$ reaction (SCR) conditions was investigated by carrying out variations in the reaction temperature, $\mathrm{SO}_{2}$ and $\mathrm{H}_{2} \mathrm{O}$ poisoning and long-term stability runs. Pt nanoparticles on the NTs exhibited superior activity compared to the $\mathrm{Cr}$, $\mathrm{Co}$ and $\mathrm{Al}$ intercalated in the nanotubes and even to the $\mathrm{Ag}$ and $\mathrm{Ni}$ counterparts. Resistance against $\mathrm{SO}_{2}$ poisoning was low on NiNT due to the trititanate phase transformation into $\mathrm{TiO}_{2}$ and also to sulfur deposits on $\mathrm{Ni}$ sites. However, the interaction between $\mathrm{Pt}^{2+}$ from $\mathrm{PtO}_{\mathrm{x}}$ and $\mathrm{Ti}^{4+}$ in the NTs favored the adsorption of both $\mathrm{NO}_{x}$ and $\mathrm{CO}$ enhancing the catalytic performance.
\end{abstract}

Keywords: $\mathrm{PtO}_{\mathrm{x}}$ species; impregnation; nanoparticles; titanate nanotubes; $\mathrm{NO}_{\mathrm{x}}$

\section{Introduction}

Titanate nanotubes are fascinating solids that have spurred significant interest as catalysts for several reactions [1,2]. These features include the metal/metal oxide intercalation or decoration that exists in titanate nanotubes, allowing their application in catalytic reactions [1-5].

Among these catalytic reactions, selective catalytic reduction (SCR) is likely to be the most effective technology for reducing nitrogen oxides, e.g., $\mathrm{NO}_{\mathrm{x}}$ emissions, owing to its simpler and continuous operation, greater flexibility for the use of reducing agents, lower costs and eco-friendliness requirements [5-11] (and references herewith). SCR using $\mathrm{NH}_{3}$ 
$\left(\mathrm{NH}_{3}-\mathrm{SCR}\right)$ as a reducing agent is especially effective in converting $\mathrm{NO}_{\mathrm{x}}$ along with its distinctive way of treating exhaust gas from stationary sources and power plants [5,8-10].

Nonetheless, the $\mathrm{NH}_{3}-\mathrm{SCR}$ process is still constrained by several challenges, particularly the low resistance to $\mathrm{SO}_{2}$ and $\mathrm{H}_{2} \mathrm{O}$ poisoning and the formation of ammonium sulfates deposit on the surface of the commercial $\mathrm{V}_{2} \mathrm{O}_{5}-\mathrm{WO}_{3}\left(\mathrm{MoO}_{3}\right) / \mathrm{TiO}_{2}$-based catalyst [5-7]. This results in the deactivation of the catalysts due to the competitive adsorption of the reactants and $\mathrm{SO}_{2}$, formation of metal and ammonium sulfates, water vapor inhibition of the acid sites, as well as production of undesired $\mathrm{NO}$ and $\mathrm{N}_{2} \mathrm{O}$ by-products from $\mathrm{NH}_{3}-\mathrm{SCR}$ reaction instead of nitrogen, the desired compound [8,9].

Numerous researchers have attempted to improve SCR processes by optimizing the physicochemical properties of the catalysts and changing reducing agents. Nowadays, substantial interest has been devoted to the SCR using hydrocarbons (HC-SCR), e.g., $\mathrm{CH}_{4}$, $\mathrm{C}_{3} \mathrm{H}_{6}, \mathrm{C}_{4} \mathrm{H}_{10}$ among others as the primary reductants for controlling $\mathrm{NO}_{\mathrm{x}}$ emissions over a variety of catalysts [12-14]. In this context, CO-SCR is a very versatile reaction between nitrogen oxide and carbon monoxide, whereby the reactants can be further transformed into nitrogen and carbon dioxide (Figure A1, Appendix A).

Supported transition metal catalysts, particularly those possessing dispersed active sites on titania, alumina, silica, ceria, molybdena, zirconia, molecular sieves, zeolites and lantana have long been used as catalysts for the CO-SCR reaction [6,13-16] (and references herewith). However, the use of these catalysts in the presence of $\mathrm{SO}_{2}$ and water vapor poisons, especially in low-temperature regimes, results in a considerable loss of activity and deactivation of catalysts, besides the complicated poisoning of the active sites by $\mathrm{SO}_{2}$ to form transition stable and inert metal sulphates on the surface of the catalysts $[8,14-19]$.

Currently, $\mathrm{Cu}, \mathrm{Pt}, \mathrm{Ni}, \mathrm{Mn}, \mathrm{Pd}, \mathrm{Rh}, \mathrm{Ag}$ oxides have been commonly used as active components of the catalysts for the decomposition of $\mathrm{NO}_{x}$ through SCR reactions. Moreover, it is shown that the introduction of promoters into the catalysts and the removal of reaction inhibitors during the SCR avoiding side reactions enhance the catalytic performance $[6,8]$ (and references herewith).

Amongst these catalysts, metal-containing titanate nanotubes have shown significant enhancement in the catalytic efficiency for decomposition of $\mathrm{NO}_{\mathrm{x}}$ reactions, regarding selectivity and yield to $\mathrm{N}_{2}$ and carbon monoxide products ([8-10,20-24] and references herewith). With the use of metal center intercalated into the titanate nanotubes structure, the $\mathrm{NH}_{3}$-SCR reaction proceeds in the presence of a bifunctional catalyst through the formation of intermediate species such as hydrogen cyanide $(\mathrm{HCN})$, isocyanate $(-\mathrm{NCO})$, nitromethane $\left(\mathrm{CH}_{3} \mathrm{NO}_{2}\right)$ and oxygenated hydrocarbons $\left(\mathrm{C}_{\mathrm{x}} \mathrm{H}_{\mathrm{y}} \mathrm{O}_{\mathrm{z}}\right)[5,8,18]$, which are accompanied by nitrogen and carbon dioxide.

Although these solids have gathered much information, they did not show details about the catalyst's active site features, neither it was proposed proper reaction conditions to apply the solids. Moreover, the mechanistic consideration of the role of the metal sites remains under debate. Therefore, there is still interest in developing titanate nanotubesbased catalysts for the CO-SCR to define the role of the different metal sites in the catalytic performance and gain insights into the best parameters for this reaction.

However, to the best of our knowledge, no reports are given on the use of metalcontaining titanate nanotubes for the CO-SCR reaction.

In this paper, for the first time, the properties of titanate nanotubes were systematically studied by introducing different transition-metal ions and evaluated in the CO-SCR reaction. Moreover, the tubular morphology of NTs offers the advantages of the nanotubes acting as nanoreactors for chemisorption of the reactants during $\mathrm{NO}_{\mathbf{x}}$ conversion through CO-SCR reaction, as compared to bulk $\mathrm{TiO}_{2}$ and Ti-based nanoparticles counterparts.

The effects of the metal intercalated into the titanate nanotubes and their dispersions and tolerance to poisons on the catalytic performances are investigated during CO-SCR reaction. 


\section{Experimental Part}

\subsection{Materials}

$\mathrm{TiO}_{2}$ anatase powder, chromium(III) nitrate nonahydrate $\left(\mathrm{Cr}\left(\mathrm{NO}_{3}\right)_{3} \cdot 9 \mathrm{H}_{2} \mathrm{O}\right)$, cobalt(III) nitrate $\left(\mathrm{Co}\left(\mathrm{NO}_{3}\right)_{3}\right)$, nickel(II) nitrate hexahydrate $\left(\mathrm{Ni}\left(\mathrm{NO}_{3}\right)_{2} \cdot 6 \mathrm{H}_{2} \mathrm{O}\right)$, aluminum(III) nitrate nonahydrate $\left(\mathrm{Al}\left(\mathrm{NO}_{3}\right)_{3} \cdot 9 \mathrm{H}_{2} \mathrm{O}\right)$, silver(I) nitrate $\left(\mathrm{AgNO}_{3}\right)$ salts and aqueous sodium hydroxide solution ( $\mathrm{NaOH}(\mathrm{aq}), 10 \mathrm{~mol} \cdot \mathrm{L}^{-1}$ ) were purchased from Vetec (Vetec, São Paulo, Brazil). The hexachloroplatinic acid solution $\left(\mathrm{H}_{2} \mathrm{PtCl}_{6} \cdot 6 \mathrm{H}_{2} \mathrm{O}\right.$ solution $8 \mathrm{wt} \%$ in water) was purchased from Sigma-Aldrich (Sigma-Aldrich, St. Louis, MO, USA). All reactants were used as received.

\subsection{Synthesis of the Catalysts}

Titanate nanotubes (NTs) were synthesized by a hydrothermal method [2,25]. Typically, a solution containing $10 \mathrm{~mol} \cdot \mathrm{L}^{-1}$ of sodium hydroxide was added to two grams of $\mathrm{TiO}_{2}$ anatase $(25 \mathrm{mmol})$ with constant stirring. Then, the mixture was placed in a Teflon container (WT Indústria, São Carlos, São Paulo, Brazil) at $160^{\circ} \mathrm{C}$ for $72 \mathrm{~h}$ in an autoclave (WT Indústria, São Carlos, São Paulo, Brazil). The solid was afterwards separated by vacuum filtration (Vacuum desiccator, Laborglas, São Paulo, Brazil) and copiously washed with deionized water to remove the excess amount of hydroxyl ions. Finally, the catalyst was dried at $50{ }^{\circ} \mathrm{C}$ overnight to obtain the sodium-containing trititanate nanotubes powder (NaNT).

Metal-containing titanate nanotubes (MeNT) were prepared by ion-exchange using aqueous solutions of chromium(III), cobalt(III), nickel(II), silver(I) and aluminum nitrate salts with the addition of ammonia solution (Neon, Suzano, São Paulo, Brazil). Afterwards, the NTs were dispersed in the aforesaid solutions under stirring. Then, the mixture was either stirred or submitted to ultrasonic bath (Prevtech, São Paulo, Brazil) to allow a better dispersion and ions diffusion. Thereafter, the mixture was thoroughly washed with deionized water and a diluted ammonia solution till the $\mathrm{pH}=7$ to remove the ions physically adsorbed on the NTs surface. Finally, the solids were dried at $80^{\circ} \mathrm{C}$ for $2 \mathrm{~h}$. The corresponding metal cations had a metal loading of ca. $1.2 \mathrm{wt} \%$, where CoNT, CrNT, NiNT, AgTNT and AlNT denote the cobalt, chromium, nickel, silver and aluminum incorporated into the NTs, respectively.

The wetness impregnation method was used to incorporate Ag and Pt into the titanate nanotubes by using the corresponding aqueous solution of silver nitrate and hexachloroplatinic acid solutions to produce AgNT and PtNT catalysts, respectively. The theoretical content of the metals was $1.0 \mathrm{wt} \%$. All catalysts were heated under He/oxygen flow, prior to their use.

\subsection{Characterizations of the Catalysts}

X-ray diffraction (XRD) patterns of the solids were recorded on a Shimadzu XRD6000 (Shimadzu, Osaka, Japan) diffractometer, which was equipped with $\mathrm{CuK} \alpha$ radiation at $40 \mathrm{kV}$ and $30 \mathrm{~mA}$. The measurements were obtained at wide angles with $2 \theta$ values varying from 5 to $70^{\circ}$. The patterns were compared to those of Joint Committee on Powder Diffraction (JCPDS).

The nitrogen adsorption-desorption isotherms were measured using an ASAP $2000 \mathrm{Mi}$ cromeritics equipment (Micrometrics, Norcross, GA, USA). Prior to the analysis, samples were degassed at $150{ }^{\circ} \mathrm{C}$ for $12 \mathrm{~h}$. The specific surface areas were determined by BrunauerEmmet-Teller (BET) method, and the pore size distributions were calculated by BarretJoyner-Halenda (BJH) method to the desorption branch of the isotherms.

The morphology of the solids was examined by Scanning electron microscopy measurements in a Quanta-FEG FEI electron microscope equipped with an EDX Link Analytical QX-20,000 system (FEI Quanta, Hillsboro, OR, USA) coupled to the SEM microscope (SEMEDS). The acceleration voltage used was $2 \mathrm{kV}$. Previous dispersion of the spent catalysts in an aluminum sample holder and sputtering the catalysts with gold (Sigma-Aldrich, St. Louis, MO, USA) were performed. 
Electron paramagnetic resonance (EPR) spectra of the samples were measured by a Bruker spectrometer (Bruker, Rheinstetten, Germany) to detect the local environment of iron atoms and valence states. The EPR measurements were performed at the X-band microwave frequencies close to $9.5 \mathrm{GHz}$. The apparatus has a double cavity with high frequency modulation of $100 \mathrm{kHz}$. Before the measurements, the samples were placed in quartz tubes of $4 \mathrm{~mm}$ inner diameter at room temperature.

The microstructures of selected titanate nanotubes were observed using transmission electron microscopy (TEM) using a JEOL JEM 2010 microscope (JEOL, Tokyo, Japan) operating at $200 \mathrm{kV}$. The high-resolution transmission electron microscopy micrographs (HRTEM) of the periodic structures were obtained by the Fourier method. Previously, the samples were prepared by ultrasound dispersing a certain amount of the sample in ethanol (Vetec, São Paulo, Brazil) and then dropping the suspension on a carbon-coated grid. Spent samples were characterized in a Transmission electron microscope from FEI Tecnai 20 G2 (FEI Quanta, Hillsboro, OR, USA) and JEOL JEM-2010 by using the same conditions previously mentioned.

Raman spectra of the solids were recorded on a Bruker Senterra spectrometer equipped with an Olympus BX5 microscope (Bruker, Karlsruhe, Baden-Württemberg, Germany) under ambient conditions. A $532 \mathrm{~cm}^{-1}$ laser line was used as the exciting source. The laser beam was focused on the sample surface at an intensity of approximately $10 \mathrm{~mW}$ and the focus was 100 times. The measurements were referenced to $\mathrm{Si}$ at $521 \mathrm{~cm}^{-1}$ with 16 data acquisitions in $100 \mathrm{~s}$. Some measurements were performed on a LabRam Raman spectrometer (HR Horiba Scientific, Tokyo, Japan) using a laser line of $532 \mathrm{~nm}$ to obtain the Raman spectra. The excitation source was the $532 \mathrm{~nm}$ line with the laser power was set at about $10 \mathrm{~mW}$. The spectral resolution was $4 \mathrm{~cm}^{-1}$ using an objective lens of 100 times.

Fourier transform infrared spectroscopy (FTIR) was performed in a Bruker equipment (Bruker, Rheinstetten, Germany) in the range of $4000-400 \mathrm{~cm}^{-1}$. Approximately $1 \mathrm{wt} \%$ of each sample was dissolved in $\mathrm{KBr}$ (Vetec, São Paulo, Brazil), before recording the curves.

The acid sites amounts were determined by temperature programmed of pyridine desorption of pyridine (TPD-Pyridine) followed by thermogravimetry (TG) measurements in a TGA/DSC1 Mettler Toledo equipment (Mettler Toledo, Columbus, OH, USA) coupled to a SDT 2960 from TA Instruments (New Castle, DE, USA). The amounts of the acid sites were calculated according to our previous studies [26].

X-ray photoelectron spectroscopy (XPS) experiments were performed at the PHI VersaProbe II Scanning XPS Microprobe (Minneapolis, MN, USA) in Malaga, Spain. After pre-treatment for surface oxidation, XPS analyses were used for determination the oxidation state of the elements and the detection of surface functional groups of selected spent solids. The incident radiation was monochromatic X-ray Al K $\alpha$ radiation $(200 \mu \mathrm{m}, 52.8 \mathrm{~W}, 15 \mathrm{kV}$, $1486.6 \mathrm{eV}$ ) with a charge neutralizer. The $C 1$ s line of adventitious carbon was used as reference at $284.8 \mathrm{eV}$. High-resolution spectra were recorded at a given take-off angle of $45^{\circ}$ by using a multi-channel hemispherical electron analyzer, which operates in the constant pass energy mode at $29.35 \mathrm{eV}$. Energy scale was calibrated using $\mathrm{Cu} 2 p_{3 / 2}, \mathrm{Ag} 3 d_{5 / 2}$, and $\mathrm{Au}$ $4 f_{7 / 2}$ photoelectron lines at $932.7,368.2$, and $83.95 \mathrm{eV}$, respectively. The Multipack software version 9.6.0.15 (Physical Eletronics, Chanhassen, MN, USA) was used to analyze in detail the recorded spectra. The obtained spectra were fitted using Gaussian-Lorentzian curves to have more accurate extract binding energies of the different element core levels.

\subsection{Catalytic Tests in SCR-CO Reaction}

The catalytic performances of the samples were examined for the selective catalytic reduction of $\mathrm{NO}_{x}$ by $\mathrm{CO}$ (CO-SCR). About $150 \mathrm{mg}$ of the catalysts (40-60 mesh) were introduced into the quartz fixed-bed quartz reactor (inner diameter $0.7 \mathrm{~cm}$ ) at atmospheric pressure. Previously, the catalyst was tightly closed into the reactor and pre-treated by flowing $80 \mathrm{~cm}^{3} \cdot \mathrm{min}^{-1}$ of $10 \% \mathrm{O}_{2} / \mathrm{He}$ at $250{ }^{\circ} \mathrm{C}$ for $1 \mathrm{~h}$ at a rate of $10{ }^{\circ} \mathrm{C} \cdot \mathrm{min}^{-1}$. Subsequently, the catalysts were purged with helium and finally cooled to $30^{\circ} \mathrm{C}$. Afterwards, the mixture of gases comprising of $500 \mathrm{ppm}$ of $\mathrm{NO}, 1000 \mathrm{ppm}$ of $\mathrm{CO}, 10 \% \mathrm{H}_{2} \mathrm{O}$ (when used), 
$50 \mathrm{ppm}$ of $\mathrm{SO}_{2}$ (when used) and helium as a balance were introduced into the catalytic bed. The catalytic runs were performed with a GHSV value of $48,600 \mathrm{~h}^{-1}$. The conversions of $\mathrm{NO}_{\mathrm{x}}$ and $\mathrm{CO}$ were measured by a $\mathrm{NO} / \mathrm{NO}_{2} / \mathrm{NO}_{\mathrm{x}}$ electrochemical analyzer from Seitron mold chemistry 400 (Seitron S.p.A, Mussolente, VI, Italy). The experimental test rig was depicted in our previous studies $[6,13]$.

The $\mathrm{NO}_{\mathrm{x}}$ conversions were calculated according to the equations presented in the references [13], as follows:

$$
\mathrm{NO}_{\mathrm{x}} \text { conversion }=\frac{\mathrm{NO}_{\mathrm{x} \text { in }}-\mathrm{NO}_{\mathrm{x} \text { out }}}{\mathrm{NO}_{\mathrm{x} \text { in }}} \times 100 \%
$$

where $\left[\mathrm{NO}_{\mathrm{x}}\right]=\left[\mathrm{NO}_{\mathrm{x}}\right]+\left[\mathrm{NO}_{2}\right]$, and the subscripts in and out represent the inlet and outlet concentration of $\mathrm{NO}_{\mathrm{x}}$ at steady state, respectively.

Where $\mathrm{NO}_{\text {in }}$ refer to the $\mathrm{NO}_{\text {out }}$ concentrations at the reactor inlet and outlet, respectively.

The turnover frequency (TOF) was determined the number of moles of $\mathrm{NO}_{\mathrm{x}}$ converted per mole of metal atom per second, according to the previous work [6].

The reaction rate $(\mathrm{r})$ was calculated as follows:

$$
\mathrm{r}_{\mathrm{NO}_{\mathrm{x}}}=\frac{\left[\mathrm{NO}_{\mathrm{x}}\right]_{\text {in }}-\left[\mathrm{NO}_{\mathrm{x}}\right]_{\mathrm{out}}}{\mathrm{W}_{\text {cat }} \times \text { time }}
$$

where $\left[\mathrm{NO}_{\mathrm{x}}\right]_{\text {in }}$ and $\left[\mathrm{NO}_{\mathrm{x}}\right]_{\text {out }}$ are the concentration of the gas fed in the reactor and concentration of the gas out of the reactor, respectively. $\mathrm{w}_{\text {cat }}$ represents the catalyst mass per $6 \mathrm{~h}$ of reaction time.

\section{Results and Discussion}

\subsection{Structural Characterizations}

X-ray diffraction (XRD) patterns of the solids are depicted in Figure 1a. The pristine NaNT shows four diffraction peaks at $2 \theta$ equal to 10.1, 24.3, 28.7 and $48.3^{\circ}$, attributed to the 200, 110, 211 and 020 reflection planes, respectively [25-29]. All peaks shown in the NaNT diffractogram can be indexed to the $P 21 / m$ space group from the monoclinic structure of $\mathrm{Na}_{2} \mathrm{Ti}_{3} \mathrm{O}_{7}$. According to the findings, the $\mathrm{Na}_{2} \mathrm{Ti}_{3} \mathrm{O}_{7}$ structure has an edgeshared $\mathrm{TiO}_{6}$ octahedron in a zigzag-like patterned arrangement, where the $\mathrm{Na}^{+}$ions reside between these layers and occupy two different crystallographic sites bound to the oxygen anions [26,27].

Moreover, the reflection at $2 \theta=10.1^{\circ}(200)$ is the characteristic peak of the periodic layer structure of the titanate nanotubes possessing an interlayer distance of $0.84 \mathrm{~nm}$ (Table 1). Several studies illustrate the layered structure of the titanate and silicatesbased materials [4,27]. Compared to NaNT, all solids containing metal impregnated or intercalated into the titanate nanotubes have similar features, being NiNT and AgNT exceptions. Noteworthy, the CoNT experiences a downshift of the diffraction angles of the $\mathrm{Na}_{2} \mathrm{Ti}_{3} \mathrm{O}_{7}$ phase, which is an indication of the structural disorder of the titanates due to the replacement of the Co metal cations by sodium. Consequently, there is an expansion of the (200) plane favoring the diffusion of the $\mathrm{Na}+$ ions diffusion through the interlayer and facilitates the ion exchange process.

As the layered structure of the titanate nanotubes is composed of the $\mathrm{TiO}_{6}$ octahedra, this feature allows $\mathrm{Na}^{+}$cations to diffuse and easily be exchanged by $\mathrm{Al}^{3+}, \mathrm{Cr}^{3+}$ and $\mathrm{Ni}^{2+}$ and $\mathrm{Co}^{3+}$ ones. Accordingly, the $\mathrm{Na} / \mathrm{Ti}$ ratios of the MeNT are lower than that of NaNT, which is an indication of the sodium removal of the sodium trititanate structure (Table 1). 


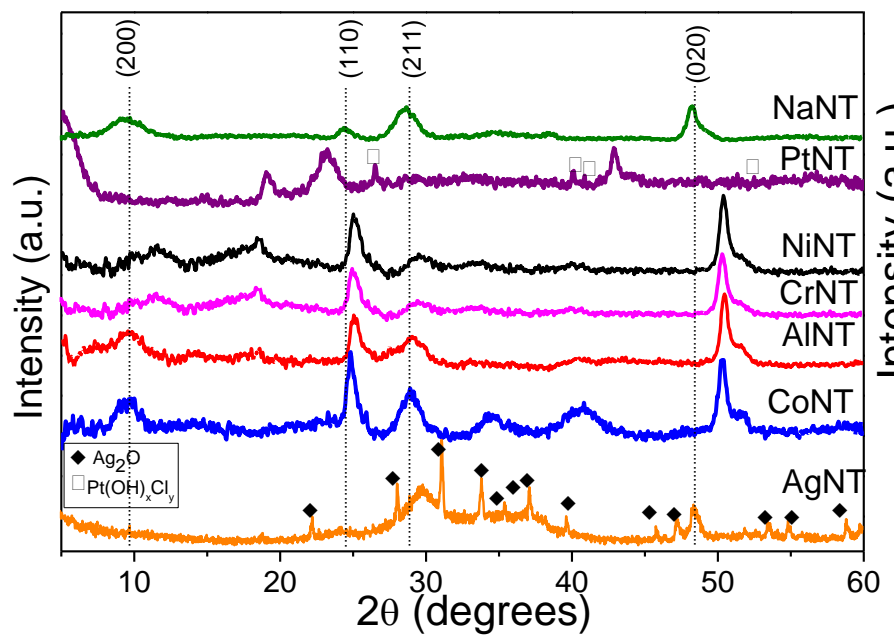

(a)

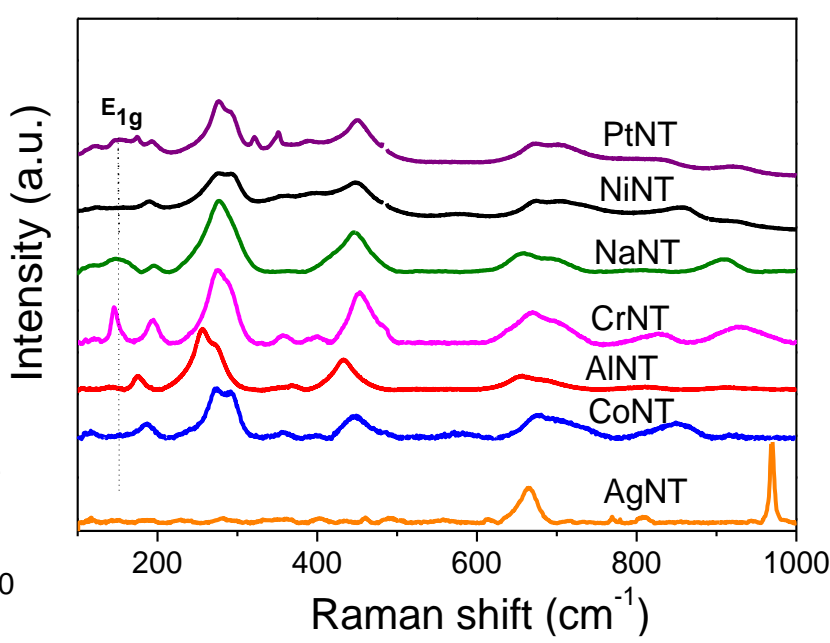

(b)

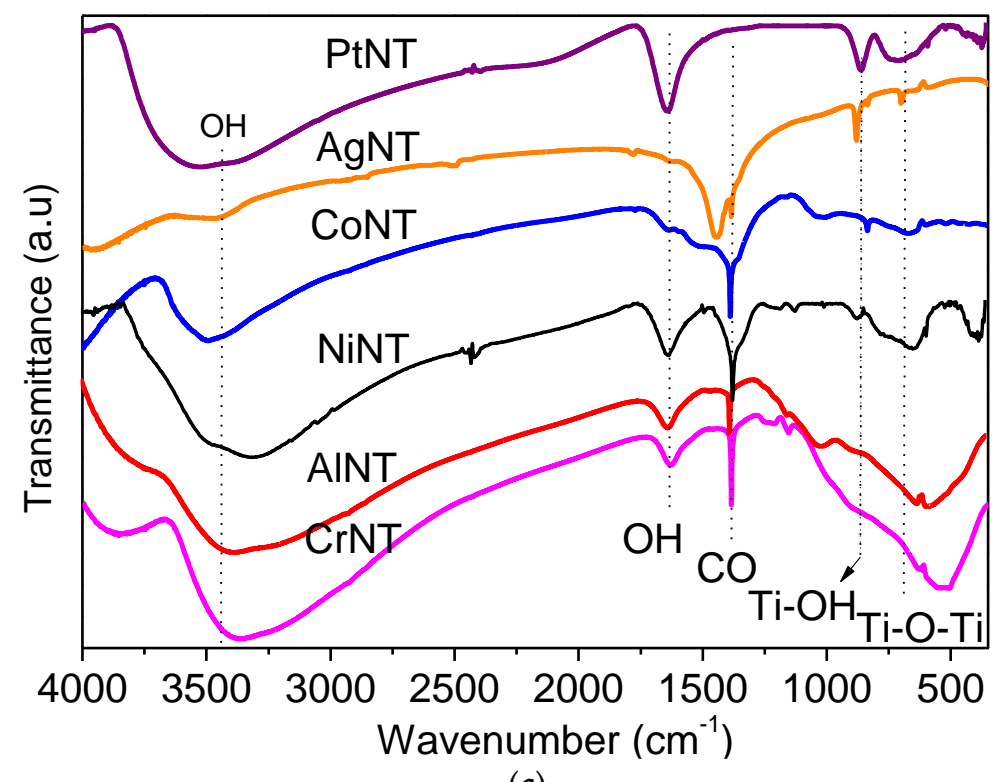

(c)

Figure 1. (a) XRD diffractograms, (b) Raman and (c) FTIR spectra of the catalysts studied. The main hkl reflections of $\mathrm{Na} 2 \mathrm{Ti} 3 \mathrm{O} 7$ are shown in parenthesis above the diffraction lines.

Table 1. Physicochemical properties of the catalysts studied. The Na/Ti molar ratios are obtained by EDS analyses whereas the interwall distances are taken through XRD measurements.

\begin{tabular}{ccc}
\hline Catalysts & $\begin{array}{c}\text { Na/Ti } \\
\text { Molar Ratio }\end{array}$ & $d^{\mathbf{b}}$ (nm) \\
\hline NaNT & 0.57 & 0.84 \\
CoNT & 0.02 & 0.91 \\
CrNT & 0.03 & 0.89 \\
AlNT & 0.06 & 0.90 \\
NiNT & 0.03 & 0.89 \\
PtNT & 0.03 & 0.90 \\
AgNT & - & - \\
\hline
\end{tabular}

a Obtained by EDS analyses; ${ }^{\mathrm{b}}$ Interwall distance determined by XRD.

Besides, NiNT solid does not show the $\mathrm{Na}_{2} \mathrm{Ti}_{3} \mathrm{O}_{7}$ tubular structure probably in reason of the fact that part of the $\mathrm{Ni}^{2+}$ species might be intercalated into the NTs structure, but 
most of these species are found in the NiOOH form on the NTs surface. This could be a result of ammonia washing during the synthesis of the solids, in agreement with the findings [29,30]. Moreover, the good dispersion of intercalated Pt nanoparticles (decorated) on the nanotubes shows that the impregnation of Pt on NTs does not significantly affect the titanate structure, implying that the scrolled titanate nanosheets remain. However, the (110) peak in PtNT diffractogram shifts to the left compared with the other catalysts due to the presence of intercalated Pt into the NTs structure. In addition, some characteristic peaks of a minor platinum contribution coming from $\mathrm{PtO}_{x}, \mathrm{PtO}_{x} \mathrm{Cl}_{y}$ or $\mathrm{Pt}(\mathrm{OH})_{x} \mathrm{Cl}_{y}$ species are observed, as found elsewhere [25,26].

In the case of $\mathrm{AgNT}$, however, the main reflections at $2 \theta=32.4$ (111), 38.1 (200) and $55.4^{\circ}$ (220) correspond to the $\mathrm{Ag}_{2} \mathrm{O}$ cubic structure (space group: $\mathrm{Pn}-3 \mathrm{~m}$ ) [31-33]. Besides that, the silver incorporation to the NTs results in a solid with high crystallinity due to the organization of the monoclinic structure of the solid. Moreover, both inner and outer surfaces of NTs have negative charges, which allow the metals to be adsorbed on these surfaces $[28,34,35]$.

Meanwhile, the AlNT catalyst exhibits low intensity peaks at $2 \theta=15.4^{\circ}(020)$ and $32.1^{\circ}(120)$, which could be ascribed to orthorhombic oxy-hydroxide boehmite $\gamma$-AlOOH structure (space group $\mathrm{Cmcm}$ ). This result is in agreement with previous findings on boehmite based materials [36]. For CoNT, the peaks at $2 \theta$ values of 10.6 (003), 19.6 (006), 35.1 (102) and $39.0^{\circ}$ (015) may depict the existence of cobalt oxyhydroxide $\mathrm{CoOOH}$ (space group of $R 3 \mathrm{~m}$ ) as a poor crystallized phase [2,37]. Furthermore, all of these extra framework reflections seem to be on the surface of the titanate nanotubes. Therefore, the adsorption of the ions on the outer surfaces is likely whereas that on interlayer is reduced due to the difficulty of the ions to diffuse into the inner surface.

Moreover, $\mathrm{CrNT}$ has a very broad peak appearing at $2 \theta$ value of $18.4^{\circ}(003)$ and another one at $2 \theta=12.4^{\circ}$ with $\mathrm{d}=0.8 \mathrm{~nm}$, which could be indexed to be from the rhombohedral structure of chromium oxyhydroxide $\alpha-\mathrm{CrOOH}$ grimaldiite phase (space group: $R-3 m$ ) as found elsewhere [2,38].

Thus, the ion-exchange of $\mathrm{Na}^{+}(102 \mathrm{pm})$ ions by a cation possessing lesser ionic radii such as $\mathrm{r}\left(\mathrm{Al}^{3+}\right)=53 \mathrm{pm}, \mathrm{r}\left(\mathrm{Cr}^{3+}\right)=84 \mathrm{pm}$ or $\mathrm{r}\left(\mathrm{Co}^{3+}\right)=61 \mathrm{pm}$ favors the metals incorporation into the NTs structure. This is consistent with the increased interwall distance of the MeNT compared with that of $\mathrm{NaNT}$ (Table 1). In contrast, $\mathrm{Ag}^{+}$having a bigger atomic radius of $\mathrm{r}\left(\mathrm{Ag}^{+}\right)=115 \mathrm{pm}$ may form an extra framework $\mathrm{Ag}_{2} \mathrm{O}$ oxide. This also suggests that a possible solid-state reaction between $\mathrm{Ag}_{2} \mathrm{O}$ and $\mathrm{Na}_{3} \mathrm{Ti}_{3} \mathrm{O}_{7}$ may take place.

Raman measurements are performed to investigate the structure of the MeNTs and the electronic interaction between Ti and metals. The region of the Raman spectrum that corresponds to the lattice vibrations is shown in Figure 1b. Accordingly, NaNT has vibrational modes at around $158(\mathrm{E} 1 \mathrm{~g}), 195$ (Eg), 276 (Ag), 445 (B1g), 656 (A1g), $696(\mathrm{Ag})$ and $908(\mathrm{Bg}) \mathrm{cm}^{-1}$ [25]. The weak bands at 156 and $192 \mathrm{~cm}^{-1}$ are attributed to the anatasetype structure of $\mathrm{TiO}_{2}$, whereas the modes at 276 and $656 \mathrm{~cm}^{-1}$ are due to the Na cation coordinated to the oxygen atom of the framework Ti-O vibration [25,35]. At $445 \mathrm{~cm}^{-1}$, the Ti-O-Ti framework vibration is clearly visible [35]. Importantly, the band at $908 \mathrm{~cm}^{-1}$ has previously been correlated with the symmetric stretching vibration mode of a short $\mathrm{Ti}-\mathrm{O}$ bond of sodium titanate in layer structure and the Ti-O-Na stretching vibration in the interlayer regions of the nanotube walls [25,34].

The spectrum of AlNT is very similar to that of NaNT, but a high downshift of the main titanate nanotubes vibrational modes confirm the structural disorder of the solid due to the $\mathrm{Al}$ insertion in the NTs structure. Moreover, an absorption band at around $360 \mathrm{~cm}^{-1}$ evidences the presence of the $\alpha-\mathrm{AlOOH}$ particles [36]. Important is to mention that the band associated with the Ag mode for AlNT splits into two shoulders at 256 and $275 \mathrm{~cm}^{-1}$, having these modes much lower intensities than those of the original Ag ones. This indicates that the replacement of the Na cation coordinated to the oxygen atom of the framework $\mathrm{Ti}-\mathrm{O}$ vibration by $\mathrm{Al}$ one provokes a hardening of the vibrational modes. These observations are consistent with the XRD results. The modes of CoNT spectrum 
upshifts comparing with that of NaNT, which indicates the softening of the modes, as Co is incorporated to the NTs structure. Similar to AlNT, the Ag modes split into two new ones illustrating the perturbation of the Ti-O bond by cobalt incorporation. Besides, the appearance of the bands with maxima at 357,406 and $582 \mathrm{~cm}^{-1}$ is assigned to the presence of $\alpha-\mathrm{CoOOH}$, as found elsewhere [37].

Interestingly, the modes of the titanates nanotubes are not affected by the presence of $\mathrm{Cr}$ in CrNT compared to NaNT, confirming that the $\mathrm{Cr}^{3+}$ ion exchange by $\mathrm{Na}^{+}$ions, in line with the $\mathrm{XRD}$ results. In other words, the titanate nanotubes bands remain virtually unperturbed upon $\mathrm{Cr}$ insertion. Moreover, the Raman bands of $\mathrm{CrNT}$ become more intense and additional modes at 361,397 and $827 \mathrm{~cm}^{-1}$ are due to the $v_{1} \mathrm{Cr}-\mathrm{O}$ symmetric stretching mode in the $\alpha-\mathrm{CrO}(\mathrm{OH})$ structure [38]. Upon the Ag addition to the NTs, the vibrational properties of the AgNT sample change substantially, as shown in Figure 1b. The titanate nanotubes bands decreased in intensity and some of them vanished from the spectrum, implying that the phase transformation of the titanate nanotube structure occurs after the silver addition. This feature indicates that silver does not participate in the bonds included in the vibrations associated with titanate nanotubes bands, most probably in the formation of the $\mathrm{Ag}_{2} \mathrm{O}$ phase. Based on XRD results, the presence of $\mathrm{Ag}_{2} \mathrm{O}$ confirms the crystallization of the AgNT catalyst. Indeed, the modes located at about 561, 700 and $1010 \mathrm{~cm}^{-1}$ are associated to the $\mathrm{Ag}-\mathrm{O}$ mode vibration, as reported in the literature [33].

The Raman spectrum of PtNT exhibits broad bands characteristic of the tubular nanotube with the layered structure of the NTs. Some of these bands depict a blueshift of the modes near $630 \mathrm{~cm}^{-1}$ due to the $\mathrm{Me}-\mathrm{O}$ bonds, as a consequence of the intercalation of the ions in the NTs structure. The findings also state that the observed blueshift can be associated with the creation of oxygen vacancies in the NTs structure [8]. Moreover, two narrow bands appear at around $350-400 \mathrm{~cm}^{-1}$, which can be ascribed to the formation of the $\mathrm{PtO}_{x}, \mathrm{PtO}_{\mathrm{x}} \mathrm{Cl}_{\mathrm{y}}$ and $\mathrm{Pt}(\mathrm{OH})_{\mathrm{x}} \mathrm{Cl}_{\mathrm{y}}$ phases [26].

FTIR spectroscopic investigation of the as-synthesized catalysts (Figure 1c) show the strong absorption band at $3600 \mathrm{~cm}^{-1}$ corresponding to the stretching vibrations of the $\mathrm{OH}$ groups from the Ti-OH bonds of the trititanate structure [39,40]. Moreover, these $\mathrm{OH}$ groups can be attributed to either physically adsorbed water or the extra framework hydroxides such as $\alpha-\mathrm{CrOOH}, \alpha-\mathrm{CoOOH}, \mathrm{NiOOH}, \alpha-\mathrm{AlOOH}$ and $\mathrm{Pt}$ species, in agreement with XRD and Raman results. Most likely, the low concentration of OH groups of AgNT is illustrated by the small size of the aforesaid absorption band, which is evident from the XRD measurements. At $1620 \mathrm{~cm}^{-1}$, the weak infrared bands with bending vibrations are assigned to the $\mathrm{OH}$ groups in all solids [39]. It should be pointed out that the band at $1360-1400 \mathrm{~cm}^{-1}$ arises from C-O bonds of surface carbonate species during the preparation of the solids. The presence of these surface carbonates will be confirmed later by XPS. Meanwhile, the FTIR spectra depict bands at around 707, 930 and $990 \mathrm{~cm}^{-1}$, being characteristic of the Ti-OH and Ti-O-Ti bonds from the NTs lattice vibrations [18,39]. Moreover, these bands below $500 \mathrm{~cm}^{-1}$ can be attributed the Me-O vibrations.

\subsection{Morphology and Textural Properties of the Catalysts}

The surface morphology of the catalysts is examined by SEM micrographs. Appearance of abundant nanorods mostly agglomerated is illustrated in the SEM micrograph of NaNT (Figure 2a). The EDS spectrum illustrates that the sodium, oxygen and titanium contents on the surface are, respectively, $0.45,46.7$ and $28.7 \%$. This indicates that the hydrothermal preparation method allowed the formation of the $\mathrm{Na}_{2} \mathrm{Ti}_{3} \mathrm{O}_{7}$ phase, taking into account the XRD and Raman results. Besides, the HRTEM micrograph (Figure 2b) confirms the existence of the randomly tangled nanotubes with inner empty structure and diameters varying of 3-10 nm and several hundred nanometers of length. These morphological aspects of the NTs are predictable by literature reports using similar hydrothermal synthesis methods [23,35].

The SEM micrograph of CoNT consists of disordered agglomerates of particles in the form of platelets (Figure 2c), although some nanotubes are visible in the edge of the 
plates. Taking into account the expectations that the ion-exchange of $\mathrm{Na}$ by Co results in the substitution of the sodium ions in the NTs structure, the EDS spectrum illustrates that a very low amount of Co ca. $0.7 \%$ is on solid surface. Moreover, Co is uniformly distributed throughout the solid surface. This is consistent with the Raman spectrum of the solids because it also indicates that the displacement of the bands caused by Co insertion in the NTs structure. Additionally, the CoNT morphology exhibits entangled nanotubular shaped particles with some black dots representing the Co nanoparticles decorating the nanotubes, as observed by HRTEM micrograph (Figure 2d). The measured interwall distance is $0.91 \mathrm{~nm}$ corresponding to the NTs, demonstrating the successful incorporation of Co into the NTs structure.
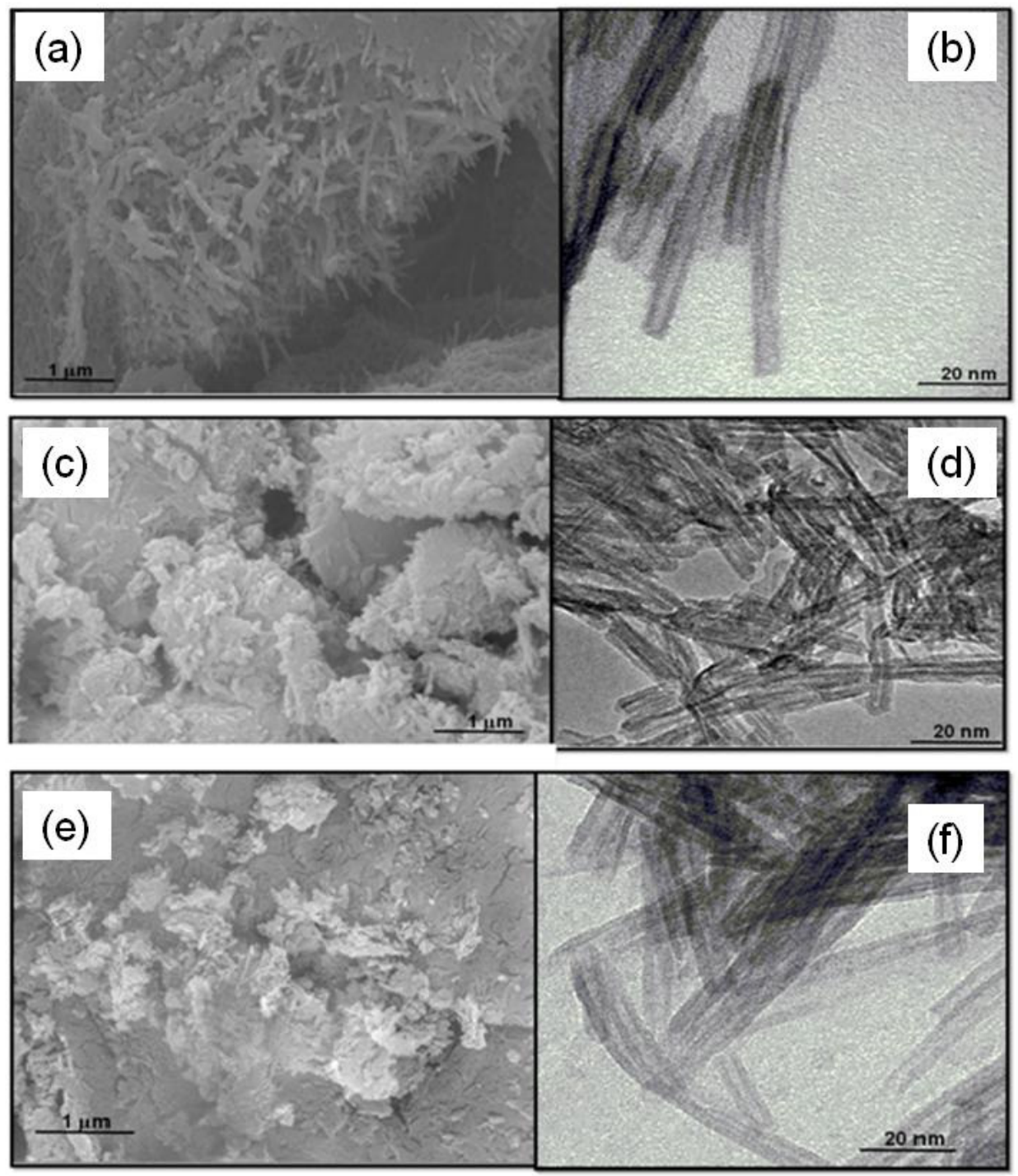

Figure 2. SEM-EDS and TEM micrographs of the catalysts studied: (a,b) NaNT, (c,d) CoNT, (e,f) CrNT.

The ion-exchange process of replacing of $\mathrm{Na}^{+}$ions by $\mathrm{Cr}^{3+}$ gives rise to agglomerated particles of irregular morphology, but some nanorods remain visible (Figure 2e). Moreover, the EDS spectrum suggests that the $\mathrm{Cr}$ content is $1.4 \%$ whereas the $\mathrm{Na}$ one is lesser than the one in $\mathrm{NaNT}$, in agreement with the low $\mathrm{Na} / \mathrm{Ti}$ ratio observed in Table 1. Most likely, the ion-exchange process does not affect the morphology of the solids with $\mathrm{CrNT}$ displaying entangled titanate nanotubes formation; however, the length of CrNT becomes short (Figure 2f).

AlNT shows particles much less morphologically similar to those observed in CrNT, with irregular shapes and the ensemble of nanotubes forming voids between the particles 
(Figure 3a). This could be an indication of the formation of large pores surrounded the particles, which is later confirmed by textural properties analyses. Although a certain amount of $\mathrm{Na}^{+}$ions is substituted by $\mathrm{Al}^{3+}$ ones in the NTs structure with the consequent drop of the sodium content, the EDS spectrum reveals that most of the Al content of ca. $1.8 \%$ is concentrated on the solid surface. Accordingly, Raman measurements suggest that the structural disorder of the AlNT due to the Al insertion in the NT structure and the presence of the $\alpha-\mathrm{AlOOH}$ phase. In particular, HRTEM micrograph of AlNT displays the interlayer distance of the ca. $0.95 \mathrm{~nm}$ pointing to the NTs structure along with the nanoparticles (black dots in Figure 3b) attributed to being boehmite.

Conversely, the SEM micrograph of the AgNT particles significantly differs from those of the other MeNTs. The formation of aggregated particles with a rough surface (Figure 3c) indicates that these particles are visually bigger than the metal-containing NTs counterparts. Moreover, small voids are observed among the particles representing the shrinkage of the NTs pores, as further seen by textural properties analyses. Moreover, the EDS spectrum confirms the presence of $0.57 \%$ of titanium along with $12.0 \%$ of $\mathrm{Na}, 54.6 \%$ of $\mathrm{Ag}$ and $24.0 \%$ of $\mathrm{O}$ atoms, respectively. This indicates that silver species are entirely deposited on the nanotubes surfaces and some nanosheets can be formed, as previously indicated by $\mathrm{XRD}$ and Raman results. Importantly, the residual sodium content is not negligible as the Ag ions deposited on solid surface. HRTEM micrograph of AGNT is seen in Figure 3d. The image clearly depicts big particles with a lattice spacing of $0.23 \mathrm{~nm}$ corresponding to the (200) plane of $\mathrm{Ag}_{2} \mathrm{O}$, as observed by XRD. These big $\mathrm{Ag}_{2} \mathrm{O}$ particles are deposited on the solid surface, but the lattice fringes of the (001) and (020) plane highlight that the monoclinic titanate nanotubes structure remains in the solid, after the ion-exchange process. The lattice fringe of $0.24 \mathrm{~nm}$ corresponding to the (111) plane of $\mathrm{Ag}_{2} \mathrm{O}$ is clearly visible.

The SEM images of NiNT are illustrated in Figure 3e,f whereas PtNT micrographs are seen in Figure 3g,h. As it can be seen, the morphology of the PtNT and NiNT surfaces is very similar to that of NaNT (Figure 2a). Nevertheless, the densification of the nanotubes can be clearly seen forming plates, which demonstrates that the ionic exchange of $\mathrm{Na}$ by $\mathrm{Ni}$ and $\mathrm{Pt}$ promotes the aggregation of the tubular morphology in a clumped manner. Notably, the $\mathrm{Ni} / \mathrm{Ti}$ and $\mathrm{Pt} / \mathrm{Ti}$ ratios measured by EDS are 0.17 and 0.18 , respectively. This implies that most of the $\mathrm{Na}$ ions $(\mathrm{Na} / \mathrm{Ti}$ ratio of $\mathrm{NaNT}$ is 0.22$)$ are removed during the ionic exchange and impregnation processes, and some $\mathrm{Pt}$ and $\mathrm{Ni}$ ions are substituted by sodium ions in the layered structure of the PtNT and NiNT.

Furthermore, TEM image of NiNT clearly illustrates that even after the ionic exchange, the tubular morphology is preserved (Figure $3 \mathrm{f}$ ), being the bundles of nanotubes entangled with Ni addition. Moreover, the morphology of the PtNT indicates that the tubular multiple-walled like morphology is still retained, but with their sizes are reduced upon $\mathrm{Pt}$ incorporation (Figure $3 \mathrm{~h}$ ).

Moreover, the $\mathrm{Ni}$ and $\mathrm{Pt}$ nanoparticles are not observable in the framework of the tubular structure indicating that they are well dispersed on both inner and outer surfaces of the nanotubes due to the electrostatic interaction between the negative charges of the NTs sheets and positively charged cations [29]. Important is to say that the nanoparticles cannot be seen due to the low resolution of the images.

These results are consistent with the XRD, Raman and FTIR measurements that suggest the maintenance of titanate nanotubes layered structures after ion exchange. On the contrary, the NiNT, PtNT and AgNT are exceptions, since their morphology is not similar to that of NaNT.

Nitrogen physisorption curves are assigned to be from type IV isotherms, which is characteristic of mesoporous materials possessing slit-shaped mesopores (Figure 4a). The $\mathrm{H} 3$ hysteresis loops of CrNT, AlNT, NiNT, PtNT and CoNT start at high relative pressure. It can indicate a remarkable porosity of the solids revealing large pore sizes and their pore connectivity, as well. This is reasonable to expect since the findings accord that the isotherms of sodic titanates nanotubes are similar to those of the metal-containing titanate nanotubes [2,19]. 

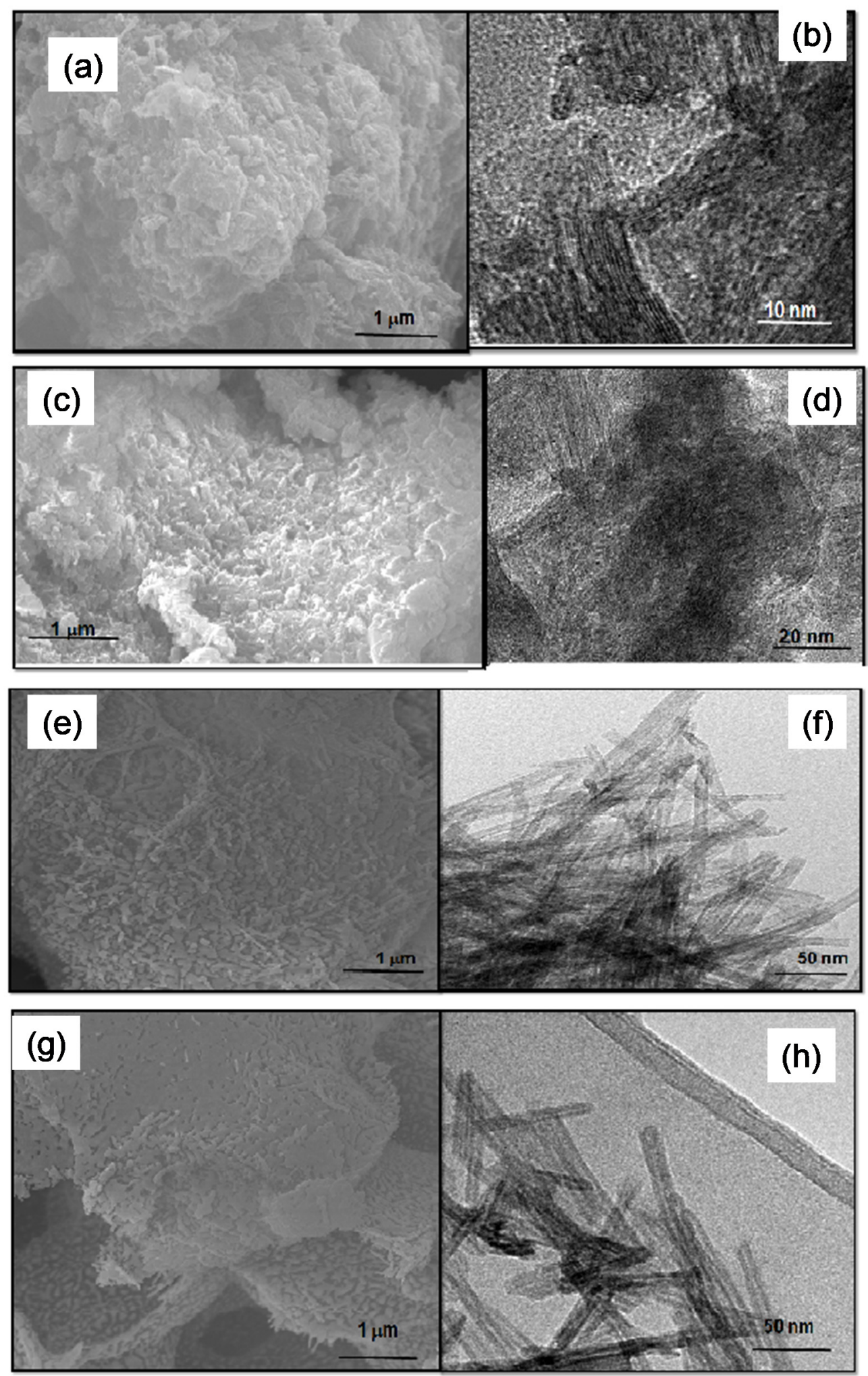

Figure 3. SEM-EDS and TEM micrographs of the catalysts studied: (a,b) AlNT, (c,d) AgNT, (e,f) NiNT and $(\mathbf{g}, \mathbf{h})$ PtNT. The included Figure in TEM image of PtNT is related to the Pt nanoparticles. 


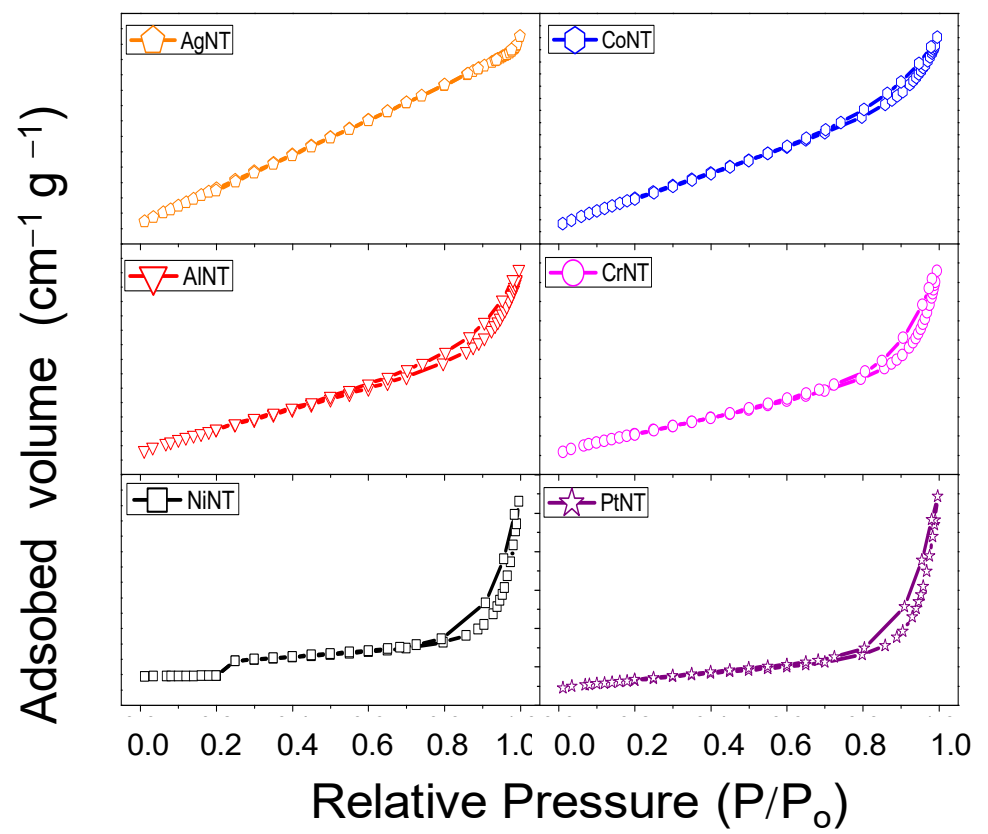

(a)

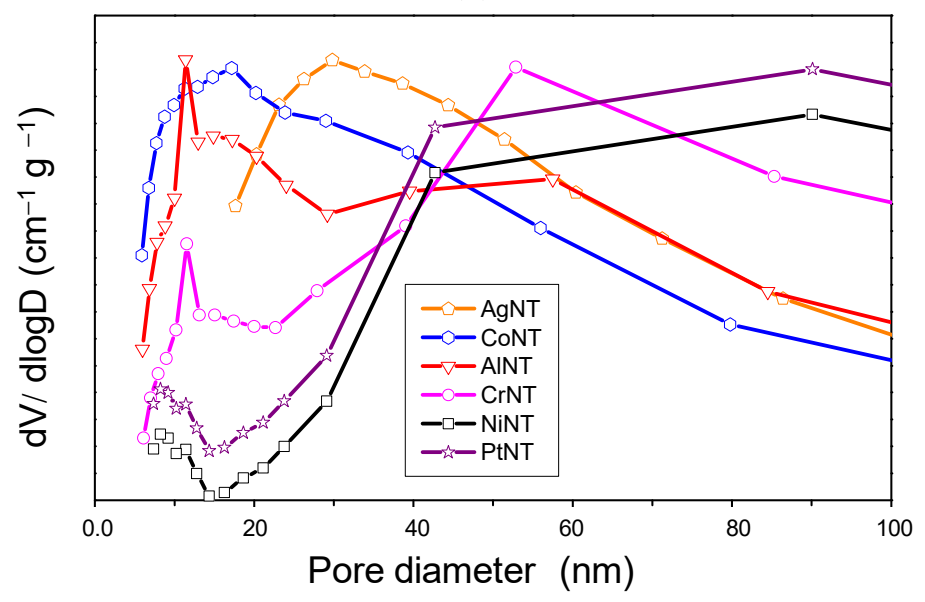

(b)

Figure 4. (a) $\mathrm{N}_{2}$ adsorption-desorption isotherms and (b) BJH pore size distributions of the catalysts.

On the contrary, the appearance of an $\mathrm{H} 4$ hysteresis loop for AgNT suggests that the solid has large particles compared to the other MeNT, which is consistent with previous results of SEM-EDS, XRD, TEM and Raman spectroscopy. The BET surface area of NaNT is $189 \mathrm{~m}^{2} \cdot \mathrm{g}^{-1}$ and the pore volume is of $0.62 \mathrm{~cm}^{3} \cdot \mathrm{g}^{-1}$, as shown in Table 2. The textural properties of the MeNT depict significant quantitative differences in the parameters, when the Me are incorporated into NTs structures. Especially for CoNT, NiNT and AlNT, the surface area and pore volume become much higher than that of NaNT, as a result of the increased interwall distance (Table 1) experienced by the introduction of $\mathrm{Al}, \mathrm{Ni}$ and Co into the interlayer region.

The results in Table 2 also illustrate a trend of declining of the textural properties values for PtNT, CrNT and AgNT compared to the Ni, $\mathrm{Al}$ and Co substituted titanate nanotubes. This result can be correlated to the formation of nanoparticles on the solid surfaces of PtNT and CrNT.

For AgNT, the deposition of the $\mathrm{Ag}_{2} \mathrm{O}$ on the NTs surface for the solid might be caused by the strong electronic interactions of the bigger Ag particles and the nanotubes surface rather than the Ag ions bound in the NTs lattices. 
Table 2. Textural properties determined from the nitrogen physisorption isotherms for the catalysts studied.

\begin{tabular}{cccc}
\hline Catalyst & $\begin{array}{c}\text { BET Surface } \\
\text { Area } \\
\left(\mathbf{m}^{\mathbf{2}} \cdot \mathbf{g}^{-\mathbf{1}} \mathbf{)}\right.\end{array}$ & $\begin{array}{c}\text { Pore } \\
\text { Volume } \\
\left(\mathbf{c m}^{\mathbf{3}} \cdot \mathbf{g}^{-\mathbf{1}}\right)\end{array}$ & $\begin{array}{c}\text { Pore Diameter } \\
(\mathbf{n m})\end{array}$ \\
\hline NaNT & 189 & 0.62 & 15 \\
CoNT & 468 & 0.77 & 5.9 \\
AlNT & 482 & 0.89 & 6.3 \\
CrNT & 293 & 0.65 & 7.8 \\
PtNT & 180 & 0.59 & 5.9 \\
NiNT & 217 & 0.71 & 6.3 \\
AgNT & 206 & 0.18 & 4.3 \\
\hline
\end{tabular}

Furthermore, the CoNT, AlNT and CrNT have considerably higher pore volume values than that of the NaNT indicating the expansion of the pores due to the metal incorporation into the inner and outer surfaces of the NTs structures. Moreover, all the pore size distribution curves exhibit broad features that can be reasoned as the presence of large mesopores (Figure 4b). Among the investigated solids, the deposition of the silver oxide particles mainly affects the pores with their consequent blocking and formation of micropores, in line with SEM-EDS and TEM results.

\subsection{Electronic States, Reduction Behavior and Acidity of the Catalysts}

Electron Paramagnetic Resonance (EPR) spectroscopy is a standard and non-destructive tool to determine the valence state of some elements of the studied catalysts. The EPR spectra of the samples exhibit two asymmetric signals centered at 2000 and $3600 \mathrm{G}$, which is typical for metal oxides paramagnetic species. Despite the fact that the EPR spectra of titanate nanotubes do not differ in shape, there are considerable differences among them. For instance, EPR line of CoNT is much broader than that of CrNT (Figure 5a) probably due to the local atomic and electronic structure of $\mathrm{Cr}$ in the NTs and interaction mechanisms between spins, as well. Indeed, the broad line shape of CrNT depicts the well asymmetrical defined doublet with $g$ value of 5.04. It is found that the paramagnetic lines of the EPR spectrum can be undoubtedly assigned to $\mathrm{Cr}^{3+}$ species $(\mathrm{r}=0.61 \AA$ ) partially occupying the positions of $\mathrm{Ti}^{4+}$ in the NTs lattice.

For the sake of comparison, trivalent chromium species in a structurally related Cr-doped $\mathrm{TiO}_{2}$ solid shows high spin configuration where a substitutional $\mathrm{Cr}^{3+}$ species occupies the vacant tetragonal $\mathrm{Ti}^{4+}$ sites environment, which are coordinated by a slightly distorted octahedron of oxygen [41]. This is corroborated by Raman results, demonstrating the existence of $\mathrm{Cr}$ in the NTs framework and $\mathrm{CrOOH}$ species.

The $\mathrm{Ti}^{3+}$ species from NTs are observable through the resonance signal with $\mathrm{g}$ values close to 2.0, as found elsewhere [42,43]. Moreover, the paramagnetic defects of the foreign species are embedded in the titanate nanotubes structure possessing a lower symmetry [44]. For, AgNT (Figure 5a), two isotropic bands doublet signals at around 2500 and $3200 \mathrm{G}$ are ascribable to the isolated $\mathrm{Ag}^{+}$ions and $\mathrm{Ag}$ coordinated to oxygen on the NTs surface [45].

For CoNT, the $\mathrm{Co}^{3+}$ ions are included into the monoclinic layered trititanate structure as a result of the $\mathrm{Na}^{+}$substitution in the interlayer region. The $g$ value of 4.9-5.4 indicates that the solid contains $\mathrm{Co}^{2+}$ and $\mathrm{Co}^{3+}$ species. On the bases of the findings reported so far, $\mathrm{Co}^{2+}$ can be incorporated in the framework of trititanate nanotubes occupying octahedral sites and substituting partially the $\mathrm{Ti}^{4+}$ ions, as well $[46,47]$. Although the differences in the atomic radius of $\mathrm{Co}^{2+}$, e.g., $\mathrm{r}=0.745 \AA$ and $\mathrm{Co}^{3+}$, e.g., $\mathrm{r}=0.61 \AA$ when replacing the $\mathrm{Ti}^{4+}$, e.g., $\mathrm{r}=0.605 \AA$ into the $\mathrm{TiO}_{6}$ octahedra exists, it is believed that the trivalent one may be visibly incorporated in the NTs framework due to its size being close to that of titanium. In agreement, EDS indicates the surface of the solid has Ti and $\mathrm{O}$ in trivial amount besides the Co incorporated in the NTs structure. 

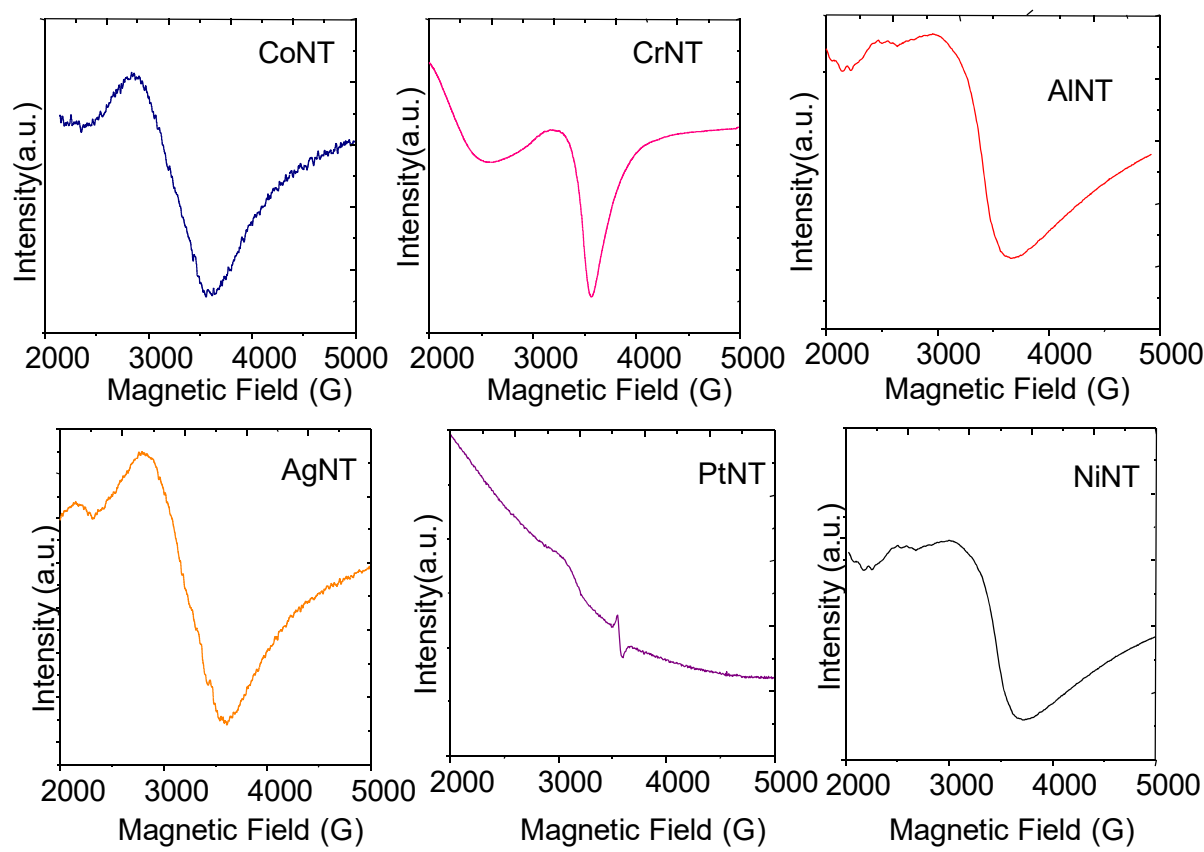

(a)
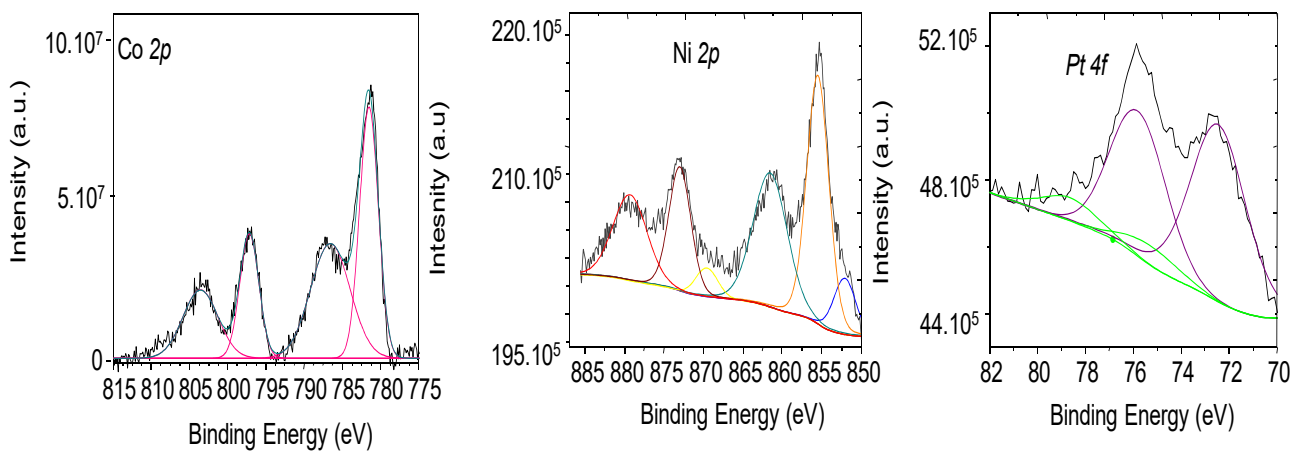

(b)

Figure 5. (a) EPR spectra of the studied of catalysts. (b) XPS spectra of the Co $2 p, \mathrm{Ni} 2 p$ and Pt $4 f$ core level, respectively, for CoNT, NiNT and PtNT.

The EPR results of AlNT and NiNT depict similar features to those of CoNT with asymmetric signals associated with isolated Me ions. Especially for PtNT, the EPR spectrum has narrow anisotropic EPR signals, which is attributed to the Pt species in accordance with the $\mathrm{Pt} / \mathrm{TiO}_{2}$ samples [48]. The reports also show that the oxygen vacancies of $\mathrm{TiO}_{2}$ surfaces are identified with $g$ values close to 2.0 which is in agreement with our XRD results.

Table 3 summarizes the results of the XPS, data of selected samples. On the basis of the XPS results, all the studied titanate nanotubes possess $\mathrm{Ti}^{4+}$ on solid surface. The Ti $2 p$ core level spectra display a doublet Ti $2 p_{3 / 2}$ and Ti $2 p_{1 / 2}$ at two main peaks at 458.7 and $465.1 \mathrm{eV}$, respectively, typical of $\mathrm{Ti}^{4+}$ in $\mathrm{TiO}_{2}$. According to previous literature on titanate nanotubes, these values were also observed for the walls of $\mathrm{Ti}_{3} \mathrm{O}_{7}{ }^{2-}$ trititanate structure with cations intercalated $[4,26]$. All of the solids have almost identical binding energies for Ti $2 p$ core level. Moreover, the remaining sodium content still visible on the surface of the NTs with Binding Energy (BE) for Na 1s being 1071.4-1071.6 eV form the remaining $\mathrm{Na}^{+}$ bonded to titanate structure (Table 3), in agreement with EDS analyses. Notably, the O 1s signals have $91 \%$ of the contribution (Figure A2, Appendix A) appearing at $530.3 \mathrm{eV}$. This signal is assigned to lattice oxygen in the NTs studied, which is indicative of either lattice oxygen of $\mathrm{TiO}_{2}$ or sodium trititanate structure, in line with the literature reports [25,26]. Moreover, the minor contribution arises at $532.2 \mathrm{eV}$, which suggests the presence of the 
oxygen from $\mathrm{OH}$ groups of the NTs and the extra framework $\mathrm{NiOOH}, \mathrm{CoOOH}, \mathrm{Pt}(\mathrm{OH}) \mathrm{Cl}_{\mathrm{x}}$ species as shown in NiNT, CoNT and PtNT, respectively. This agrees with the FTIR spectra that showed the presence of $\mathrm{OH}$ groups.

Table 3. Binding Energies (in eV) of the C 1s, Ti $2 p_{3 / 2}, \mathrm{O} 1 s$, Na $1 s, \mathrm{Co} 2 p_{3 / 2}, \mathrm{Pt} 4 f_{7 / 2}$ and Ni $2 p_{3 / 2}$ signal for the studied catalysts.

\begin{tabular}{|c|c|c|c|c|c|c|c|}
\hline Catalysts & $\mathrm{C} 1 \mathrm{~s}$ & $01 s$ & Ti $2 p_{3 / 2}$ & $\mathrm{Na} 1 s$ & Co $2 p_{3 / 2}$ & $\mathrm{Ni} 2 p_{3 / 2}$ & $\operatorname{Pt} 4 f_{7 / 2}$ \\
\hline CoNT & $\begin{array}{c}284.8(76) \\
286.6(18) \\
289.1(6)\end{array}$ & $\begin{array}{c}530.3(91) \\
532.2(9)\end{array}$ & 458.7 & 1071.4 & 781.0 & - & - \\
\hline NiNT & $\begin{array}{c}284.8(73) \\
286.6(18) \\
289.1(9)\end{array}$ & $\begin{array}{c}530.3(91) \\
532.1(9)\end{array}$ & 458.6 & 1071.6 & - & 855.9 & - \\
\hline PtNT & $\begin{array}{l}284.8(70) \\
286.6(12) \\
289.1(18)\end{array}$ & $\begin{array}{c}530.3(91) \\
531.9(9)\end{array}$ & 458.7 & 1072.0 & - & - & $\begin{array}{l}72.5(88) \\
75.3(12)\end{array}$ \\
\hline
\end{tabular}

For CoNT samples, the Co $2 p$ core level has two broad peaks (Figure $5 b$ ) illustrating the typical Co $2 p_{3 / 2}-\mathrm{Cr} 2 p_{1 / 2}$ doublet. The binding energy values for the Co $2 p_{3 / 2}$ and $2 p_{1 / 2}$ core levels are at around 781.0 and $796.0 \mathrm{eV}$ assigning the presence of $\mathrm{Co}^{2+}$ in tetrahedral coordination state and shake-up satellites, respectively. However, the presence of $\mathrm{Co}^{3+}$ species cannot be ruled out $[13,25]$. The satellite indeed indicates the $\mathrm{Co}^{2+}$ greatly interacting with $\mathrm{OH}$ groups from $\mathrm{CoOOH}$ phase. This is in accordance with XRD and Raman EPR results of the solids.

The Ni $2 p$ core level spectrum for NiNT presents the main Ni $2 p_{3 / 2}$ peak at $855.9 \mathrm{eV}$ corresponding to the $\mathrm{Ni}^{2+}$ state. This indicates that the structure of the trititanate nanotubes is preserved with $\mathrm{Ni}$ intercalated into the titanate interlayer. The $\mathrm{Ni} 2 p_{3 / 2}$ shake up satellite peak $861.2 \mathrm{eV}$ suggests the presence of $\mathrm{Ni}^{2+}$ in $\mathrm{NiOOH}$, as observed by XRD and EPR results.

The Pt $4 f$ core level spectrum for the PtNT sample exhibits an asymmetric $\mathrm{Pt} 4 \mathrm{f}_{7 / 2}$ peak that can be decomposed into two contributions at $72.5 \mathrm{eV}(88 \%)$ and $75.3 \mathrm{eV}(12 \%)$, as shown in Figure $5 \mathrm{~b}$. The components at 72.5 and $75.3 \mathrm{eV}$ arise from $\mathrm{Pt}^{2+}$ and $\mathrm{Pt}^{4+}$ species, respectively, in either $\mathrm{Pt}$ oxides or $\mathrm{Pt}(\mathrm{OH}) \mathrm{Cl}_{\mathrm{x}}$ form $[13,25,49]$. More importantly, the $\mathrm{Cl} 2 p$ core level spectrum for PtNT shows the doublet $\mathrm{Cl} 2 p_{3 / 2}$ and $\mathrm{Cl} 2 p_{1 / 2}$ at 199.0 and $200.6 \mathrm{eV}$, respectively; this is typical of $\mathrm{Pt}(\mathrm{OH}) \mathrm{Cl}_{\mathrm{X}}$ species $[13,49]$.

The presence of $\mathrm{Ni}^{2+}$ ions as intercalated nickel species is confirmed in NiNT spectrum whereas PtNT shows $\mathrm{Pt}$ species in two valence state such as $\mathrm{Pt}^{2+}$ and $\mathrm{Pt}^{4+}$ ions from $\mathrm{PtO}$ and $\mathrm{Pt}(\mathrm{OH}) \mathrm{Cl}_{\mathrm{x}}$, respectively. In the case of $\mathrm{CoNT}$, the $\mathrm{Co}^{2+}$ species are found by XPS. This is expected taking into consideration the ion-exchange and impregnation processes used to obtain the titanate nanotubes.

The TPR measurements of fresh NiNT, PtNT and CoNT were previously published $[4,25]$. As a summary in Table 4, the TPR pattern of NiNT depicts a broad signal in the $400-600{ }^{\circ} \mathrm{C}$ range, which is associated with $\mathrm{NiO}$ strongly interacting with the NTs support during the reduction of the solid, as shown previously [4]. Contrary, the CoNT exhibits a less reducible species at temperatures as low as $200{ }^{\circ} \mathrm{C}$. This indicates that some $\mathrm{Co}^{2+}$ species are not incorporated into the NTs and low interacting with the NTs support whereas the peak at high temperatures suggests the reduction of the Co nanoparticles highly dispersed on solid surface forming the surface like $\mathrm{Co}_{3} \mathrm{O}_{4}$ phase.

In the case of TPR curve of PtNT, two reduction stages are observed at $200{ }^{\circ} \mathrm{C}$ and up to $700{ }^{\circ} \mathrm{C}$, most probably due to the reduction of the oxychlorinated platinum species. Presumably, the second stage can be attributed to the consecutive reduction of the $\left[\mathrm{PtO}_{\mathrm{x}} \mathrm{Cl}_{\mathrm{y}}\right]$ or $\mathrm{PtCl}_{6}{ }^{-}$to $\mathrm{PtO}_{x}$ and the further reduction of these species, as found elsewhere $[25,26]$. 
Table 4. General features of the solids investigated by TPR and acidity measurements of the CoNT, NiNT and PtNT fresh solids.

\begin{tabular}{|c|c|c|c|}
\hline Catalyst & $\begin{array}{c}\text { Temperature of } \\
\text { Reducibility } \\
\text { by } \mathrm{H}_{2} \text { TPR } \\
\left({ }^{\circ} \mathrm{C}\right)\end{array}$ & $\begin{array}{c}\text { Temperature of } \mathrm{CO}_{2} \\
\text { Desorption } \\
\text { by } \mathrm{CO}_{2} \text { TPD } \\
\left({ }^{\circ} \mathrm{C}\right)\end{array}$ & 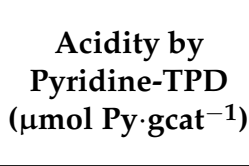 \\
\hline $\mathrm{NiNT}$ & $400-600$ & $100-300 ;>300$ & 103 \\
\hline PtNT & $200 ;>700$ & $100-250 ;>300-500$ & 261 \\
\hline CoNT & $150 ;>350$ & $100-300 ;>300$ & 93 \\
\hline
\end{tabular}

The acidity measurements by TPD-pyridine reveals that the amount of the acid sites in NaNT is about $7 \mu \mathrm{mol}$ Py gcat ${ }^{-1}$ mostly having weak acidity. Contrary, PtNT has the acid sites of medium to strong strength possessing the amount of ca. $261 \mu \mathrm{mol}$ Py gcat $^{-1}$ (Table 4). This is attributed to the surface $\mathrm{Pt}$ species such as oxidized $\mathrm{PtO}_{\mathrm{x}}(\mathrm{PtO}$ or $\left.\mathrm{PtO}_{2}\right)$ and chlorine $\left(\mathrm{Pt}(\mathrm{OH})_{\mathrm{x}} \mathrm{Cl}_{\mathrm{y}}\right.$ and $\left.\mathrm{PtO}_{\mathrm{x}} \mathrm{Cl}_{\mathrm{y}}\right)$ species [4,25]. When comparing $\mathrm{PtNT}$ and NiNT catalysts, the amount of acid sites decreases with NiNT having the minor amount of acid sites due to the weak acidity of the $\mathrm{Ni}^{2+}$ species. Thus, acidity measurements by pyridine-TPD follows the order: CoNT $<$ NiNT $<$ PtNT.

The basicity of the fresh titanates based-solids is investigated by the $\mathrm{CO}_{2}-\mathrm{TPD}$. For CoNT, the first band is located at $100-300{ }^{\circ} \mathrm{C}$ (Table 4) being related to the decomposition of the as-synthesized titanate nanotubes into $\mathrm{TiO}_{2}$ species, and possibly the adsorption of $\mathrm{CO}_{2}$ on the weak acid sites of the samples. The second peak spans from 300 to $500{ }^{\circ} \mathrm{C}$ being related to the $\mathrm{CO}_{2}$ adsorption on the medium-strength basic sites, arising from $\mathrm{NaO}_{x}$ species $\mathrm{TiO}_{2}$ or $\mathrm{CoTiO}_{3}$ phases [25]. The NiNT catalyst has low intensity desorption peak at temperatures as low as $300{ }^{\circ} \mathrm{C}$ due to the decomposition of the titanate and the formation of weak basic sites, as well. At temperatures superior to $300{ }^{\circ} \mathrm{C}$, the medium strength basic sites are observed accounting for the low interaction of Ti with $\mathrm{NiO}$. In the case of PtNT, a peak in the $100-250{ }^{\circ} \mathrm{C}$ range is due to $\mathrm{NaO}_{x}$ presence and the nanotubes decomposition [4]. The second peak arises in the $300-500{ }^{\circ} \mathrm{C}$ range assigning to the $\mathrm{CO}_{2}$ adsorption on weak Pt or Ti sites.

All these facts are evidenced by the EPR, XRD and Raman measurements of the solids shown in the previous section.

\subsection{Catalytic Results}

The catalytic evaluation of the solids in the selective reduction of $\mathrm{NO}_{x}$ by $\mathrm{CO}(\mathrm{CO}-$ SCR) reaction is carried out in the temperature range of $50-550{ }^{\circ} \mathrm{C}$. At temperatures lower than $100{ }^{\circ} \mathrm{C}, \mathrm{NO}_{\mathrm{x}}$ conversions inferior to $37 \%$ are seen for all titanate nanotubes catalysts (Figure 6). Importantly, preliminary investigations without using catalysts in blank runs afforded less than $5 \%$ of conversion at $100^{\circ} \mathrm{C}$. As $\mathrm{NO}_{x}$ can be physically adsorbed on the surface of the solids at low temperatures $[6,48]$, the subsequent increase of the activity is observed at higher temperatures.

The NaNT sample possessing $\mathrm{Ti}^{4+}$ centers from $\mathrm{Na}_{2} \mathrm{Ti}_{3} \mathrm{O}_{7}$ phase is inactive in the reaction, independently of the temperature evaluated. As the solids have residual alkali sodium contents, it can be seen that the presence of Na does not affect the catalytic performance during the CO-SCR reaction. In contrast to NaNT, the metal-containing titanate nanotubes are actives in the reaction, suggesting that the metals incorporated in the NTs work as active sites for the acid-base or redox reaction. It is noteworthy that AgNT, AlNT and CrNT exhibit similar behavior with conversions below $15 \%$ in all temperature range. Moreover, literature reports show that the catalyst having sites for $\mathrm{NO}_{\mathrm{x}}$ adsorption on the alkali elements such as $\mathrm{Na}$, protonic nanotubes and alkaline earth are active in the reaction [50-53], but the presence of a metal is needed. 


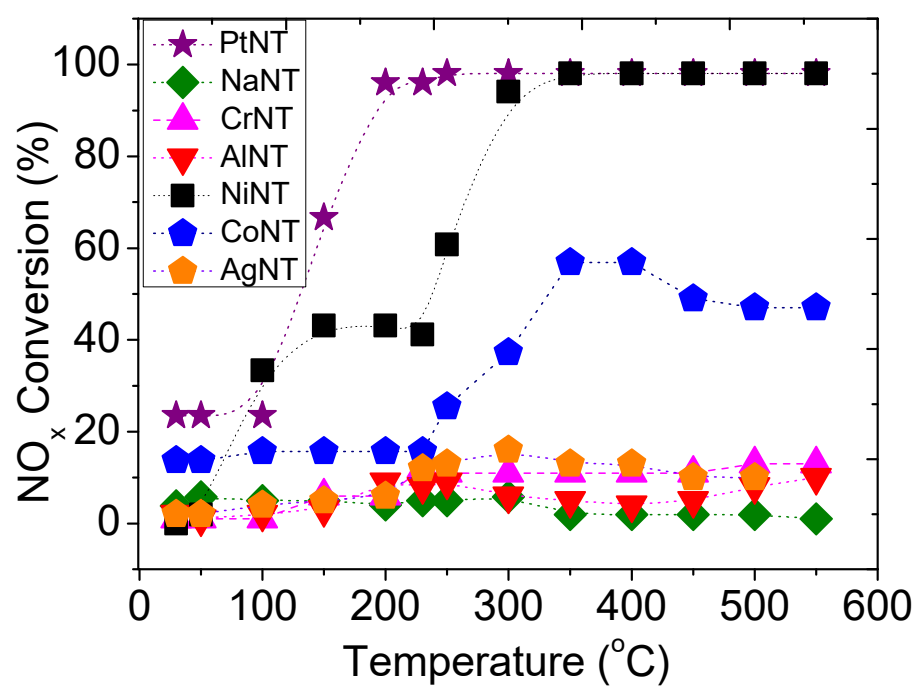

Figure 6. $\mathrm{NO}_{\mathrm{x}}$ conversions of the titanate nanotubes as a function of the temperature during CO-SCR reaction. Reaction conditions: amount of the catalyst, $0.15 \mathrm{~g}$; reaction mixture, $500 \mathrm{ppm}$ of NO, $1000 \mathrm{ppm}$ of $\mathrm{CO}$ and balance in He; flow rate, $80 \mathrm{~mL} \cdot \mathrm{min}^{-1}$; space velocity, $48,000 \mathrm{~h}^{-1}$.

Further reaction temperature increase from $100-250{ }^{\circ} \mathrm{C}$ gives distinct behavior for MeNTs solids studied. The literature reports show that the CO-SCR reaction initially proceeds by the simultaneous oxidation of $\mathrm{NO}$ to surface nitrates as strong oxidants and oxidation of the CO to surface oxygenates $[14,15]$. This next step is the reaction between these surface intermediates that leads to the formation of $\mathrm{NCO}$ and $\mathrm{CN}$ species, and finally, the latter species are converted into $\mathrm{N}_{2}$; the $\mathrm{CO}$ is oxidized to $\mathrm{CO}_{2}$ at relatively mild temperatures. Interestingly, Figure 6 shows that $\mathrm{NO}_{x}$ decomposition of all the abovementioned MeNTs is very low at temperatures as low as $200^{\circ} \mathrm{C}$, with CoNT, PtNT and NiNT being exceptions. As the reaction proceeds, the catalytic activities suddenly depict a huge upward trend for CoNT, PtNT and NiNT, when the reaction temperature rises above $250^{\circ} \mathrm{C}$. For instance, the $\mathrm{NO}_{x}$ conversion on PtNT is $25 \%$ at $100{ }^{\circ} \mathrm{C}$ and reaches $92 \%$ at $200{ }^{\circ} \mathrm{C}$ indicating the moderate temperatures causes an improvement of the catalytic properties. Contrary, the activities of AgNT, AlNT and CrNT achieve a plateau with low conversions below $10 \%$ in all temperature ranges.

Importantly, the methods of salt addition to nanotubes, i.e., ion exchange and wet impregnation affect the catalytic performance of the solids. Even though PtNT is prepared via wet impregnation method, the surface acidities of both $\mathrm{PtO}_{\mathrm{x}}$ and chlorined Pt entities on the tubular NTs play an important role on the catalytic activity, especially the strong adsorption capability of $\mathrm{Pt}$ sites toward $\mathrm{CO}$ and $\mathrm{NO}_{\mathrm{x}}$ reactants at low temperatures.

Subsequent temperature increase from 250 to $550{ }^{\circ} \mathrm{C}$ results in CoNT, PtNT and NiNT conversions close to $55 \%$ at $550{ }^{\circ} \mathrm{C}$, in opposite to NaNT, AlNT, AgNT and CrNT that experience poor performance. Taking into account the presence of the nanotube structures possessing the $\mathrm{Na}_{2} \mathrm{Ti}_{3} \mathrm{O}_{7}$ phase in these solids (identified later by XRD and Raman of the spent samples), it can be inferred that the sodic phase is thermally transformed to transition states among the trititanate, anatase $\mathrm{TiO}_{2}$ and traces of rutile $\mathrm{TiO}_{2}$ phases at about $400{ }^{\circ} \mathrm{C}[25]$.

Besides, the catalytic behavior of AlNT is apparently different from that of NaNT with $\mathrm{NO}_{x}$ conversion of $6 \%$ at $550{ }^{\circ} \mathrm{C}$. Such a behavior is considered to be caused by the $\mathrm{Al}$ centers incorporated to the titanate nanotubes that promote the CO-SCR reaction. However, a large amount of $\mathrm{Na}$ ions on solid surface (Table 1) leads to lower accessibility of the Al species, thus resulting in a very low performance of the AlNT. Notably, the AlOOH phase onto the NTs surface does not improve the catalytic performance of the solid. To verify this assumption, XRD, FTIR and Raman of the spent solids demonstrate that most of the Na ions remain on AlNT surface, while boehmite is deposited on the solid surface. 
CrNT has a $\mathrm{NO}_{x}$ conversion of ca. $15 \%$, which is considered to be close to that of AlNT and AgNT. Despite the fact that both AlNT and CrNT display almost identical interplanar distance, most of the $\mathrm{Cr}^{3+}$ ions are out of NTs lattice forming the well disperse $\mathrm{CrOOH}$ oxide. Thus, more $\mathrm{Cr}^{3+}$ appears somewhat exposed on surface, as observed from the results of XRD, SEM-EDS, EPR and Raman spectroscopy. It is interesting to note that these trivalent chromium species in extra lattices are assumed to be responsible for the modest catalytic performance of the solids, in comparison with the AgNT, and AlNTs analogues.

It is worthy to mention that a $\mathrm{NO}_{x}$ conversion of $7 \%$ is accomplished by AgNT, which is indeed two times lesser than that observed in the case of CoNT. The exposition of the $\mathrm{Ag}_{2} \mathrm{O}$ nanoparticles low interacting with the NTs surface (SEM, HRTEM and XRD) may result in a boost of the catalytic performance of the solid. These data nicely demonstrate that the $\mathrm{Ag}^{+}$species located on solid surface assists interacting with the $\mathrm{CO}$ and $\mathrm{NO}_{\mathrm{x}}$ molecules; thus, Ag species are not able to maintain the catalytic performance.

The presence of Co incorporated into the NTs structure depicts a significant influence on the activity of the CoNT catalyst. Even with a small amount of cobalt, e.g., $1.0 \mathrm{wt} \%$, the $\mathrm{NO}_{x}$ conversion is noticeably showing a clear increase of two times more than that of AlNT and AgNT. The entire inclusion of Co into the NT structure produces $\mathrm{Co}^{3+}$ sites accessible to the reactants and plays an important role in improving the $\mathrm{NO}_{\mathrm{x}}$ conversion. Conversely, the interaction of Co active sites is inefficient to retain the conversion level. Thereby, the modest performance of $\mathrm{CoNT}$ toward $\mathrm{NO}_{\mathrm{x}}$ and $\mathrm{CO}$ is found. In reference to the literature for other Co-based catalysts for SCR reactions [54], the $\mathrm{CH}_{4}-\mathrm{SCR}$ studies on Co-based zeolites demonstrate the thermodynamic equilibrium allows high $\mathrm{NO}$ conversions to $\mathrm{NO}_{2}$ by $\mathrm{O}_{2}$ below $400{ }^{\circ} \mathrm{C}$, although the catalyst is needed to the reaction occurrence.

Furthermore, the catalytic performance of the NTs is greatly improved when nickel is incorporated to the NTs. In line with expectations, note that the beneficial effects of the Ni phase on NTs at around $300{ }^{\circ} \mathrm{C}$ are those of increasing the dispersion of the titanate nanotube (further shown by TEM and FTIR measurements of the spent solids) and promoting the reduction of $\mathrm{Ni}^{2+}$ sites during the range of temperature studied (Table 4 , TPR results). Most probably, the reaction environment provides the reduction of Ni species on the defect sites of the NTs, facilitating the coordination of $\mathrm{NO}_{\mathrm{x}}$ or $\mathrm{CO}$ molecule to a $\mathrm{Ni}$ Lewis acid sites and thus improving the catalytic performance. In contrast, isolated $\mathrm{NiOOH}$ alone and those incorporated to the NTs sites in NiNT have low acidity (Table 4, acidity measurements) implying in the low efficiency of these $\mathrm{Ni}$ sites to convert $\mathrm{NO}_{\mathrm{x}}$ at temperatures lower than $200{ }^{\circ} \mathrm{C}$ (Figure 6). In line with these results, the $\mathrm{Ni}^{2+}$ is reduced above $550{ }^{\circ} \mathrm{C}$, facilitating the transformation of the $\mathrm{Na}_{2} \mathrm{Ti}_{3} \mathrm{O}_{7}$ and $\mathrm{NiOOH}$ phases to anatase and their corresponding $\mathrm{NiO}$ sites to increase the catalytic performance.

Notably, PtNT reaches the maximum values of $\mathrm{NO}_{x}$ conversion at temperatures superior to $200{ }^{\circ} \mathrm{C}$ followed by NiNT. The surface acidities of the well dispersed $\mathrm{PtO}_{\mathrm{x}}$ and chlorinated Pt entities on the tubular NTs (latter seen by TEM) give the highest acidity for the former, as shown in Table 3. Thereby, this results in high $\mathrm{NO}_{\mathbf{x}}$ conversion within lower temperature region. On the basis CO-TPSR lean trap $\mathrm{NO}_{x}$ measurements for Ptbased samples, the $\mathrm{CO}$ reacts with $\mathrm{NO}_{\mathrm{x}}$ forming $\mathrm{CO}_{2}$ and $\mathrm{NO}$, along with trace amounts of $\mathrm{N}_{2}$ above $330{ }^{\circ} \mathrm{C}$ simultaneously [3]. Moreover, our previous studies on optimizing the selective catalytic reduction of $\mathrm{NO}$ by $\mathrm{CO}$ reaction in the presence of distinct oxygen concentrations have demonstrated that the catalysts are more tolerant to the presence of oxygen in concentrations as low as 1000 ppm, which inhibit the oxidation of the CO by oxygen [55]. In agreement, the $\mathrm{CO}_{2}$-TPD profile indicates that the PtNT catalyst could avoid the oxidation of $\mathrm{CO}$, since the Pt sites have a low affinity for this molecule maintaining the $\mathrm{CO}$ as a reducing agent to react with $\mathrm{NO}_{\mathrm{x}}$ during the CO-SCR reaction.

Effect of the $\mathrm{SO}_{2}$ and Water Vapor Poisons on the Catalytic Performance

To further demonstrate the physicochemical properties of the solids on the catalytic performance, the evaluation of the temperature reaction as a function of reaction time is shown in Figure 7a. The NaNT, CrNT, AgNT and AlNT catalysts give overall unsatisfactory 
results with low conversions in $600 \mathrm{~min}$. of reaction because of their lack of structural stability. In consideration of the constraints of the catalysts, no further experiments are pursued using these MeNTs.
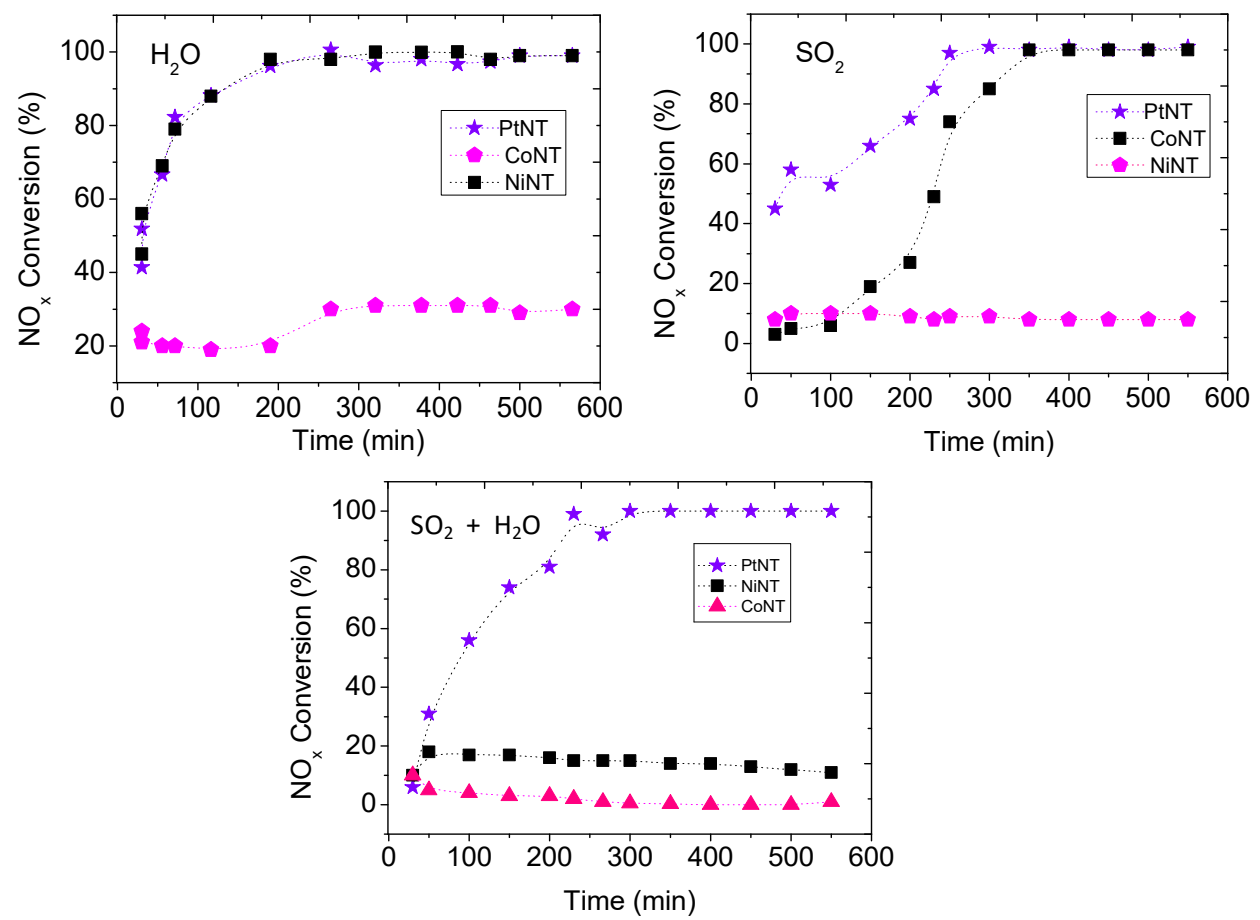

(a)

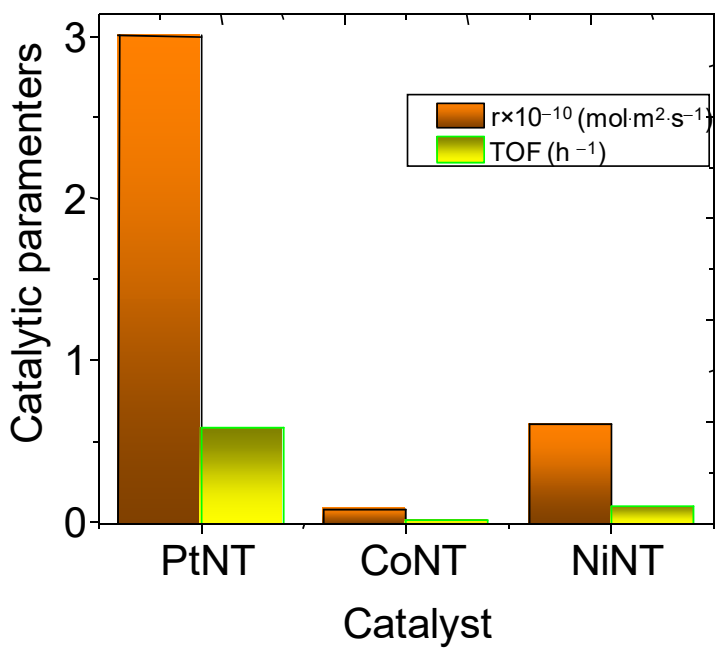

(b)

Figure 7. (a) Effects of the $\mathrm{SO}_{2}$ and water vapor poisons (or both) on the catalytic performance of the solids. Reaction conditions: amount of the catalyst, $0.15 \mathrm{~g}$; reaction gas mixture, $500 \mathrm{ppm}$ of NO, $1000 \mathrm{ppm}$ of $\mathrm{CO}$ and balance in $\mathrm{He}$; flow rate, $80 \mathrm{~mL} \cdot \mathrm{min}^{-1}$; space velocity, $48,000 \mathrm{~h}^{-1}$. Either $10 \mathrm{wt} \%(v / v)$ of water vapor or $50 \mathrm{ppm}$ of $\mathrm{SO}_{2}$ (or both) was used during the reaction at $250{ }^{\circ} \mathrm{C}$ for $600 \mathrm{~min}$. (b) Catalytic parameters determined in $6 \mathrm{~h}$ after the exposition of the solids to the $\mathrm{SO}_{2}$ and water vapor poisons.

Therefore, the catalytic runs are carried out with the NiNT, PtNT and CoNT catalysts. The data clearly indicate that the solids have distinct behavior by using the $\mathrm{SO}_{2}$ and water vapor poisons (Figure 7a). At the early stages of the reaction, activity increases by increasing the reaction time using water vapor as a poison with $\mathrm{NO}_{x}$ conversion rising from $21 \%$ in $300 \mathrm{~min}$ to $30 \%$ at the end of the reaction for CoNT. Likewise, $\mathrm{NO}_{\mathrm{x}}$ conversions over NiNT 
and PtNT are enhanced to values up to $40 \%$ in $150 \mathrm{~min}$, and the value greatly increases to $100 \%$ running the reaction beyond this time in $600 \mathrm{~min}$.Most of the findings state that the SCR reactions in the presence of water vapor poison are inhibited since the referred vapor can compete by the active sites of the catalysts through competitive adsorption causing a decay in the $\mathrm{NO}_{x}$ conversion at relatively low concentrations, e.g., 1-5\% of $\mathrm{H}_{2} \mathrm{O}$ [56-58].

On the contrary, some reports show the role of water in SCR reaction the amount of water does not further retard the SCR reaction since new hydroxyl Brønsted acid site may be created in reason of the adsorption and decomposition of water on the solid surface [57]. In response to the contradiction, the current result illustrates that the expected NTs performance with $\mathrm{NO}_{x}$ conversion is superior to $20 \%$, even upon steam introduction (Figure $7 \mathrm{a}$ ). Thus, moisture interacts with the surface of the NTs and modifies the surface-active sites and the distribution of Lewis and Brønsted acid sites, as found elsewhere [59]. Meanwhile, a steep plateau in the $\mathrm{NO}_{\mathrm{x}}$ conversion is seen in CoNT catalyst with prolonged reaction time due to Co sites oxidation by water vapor. Furthermore, the activity of NiNT and PtNT catalysts appears to be less affected by water vapor reaching up to $90 \%$ of conversion after $600 \mathrm{~min}$ of reaction. A consequence is that the structure of these trititanate catalysts is maintained after the catalytic test, as further demonstrated by spent catalyst characterizations.

PtNT and NiNT catalysts are found to be very tolerant to $\mathrm{SO}_{2}$ in CO-SCR at low temperatures. However, CoNT is less active than $\mathrm{Pt}$ and $\mathrm{Ni}$, being limited to its low resistance against sulfur poisoning, as illustrated by the poisoning experiments. Thus, PtNT and NiNT have a $\mathrm{NO}_{x}$ conversion (by 3.0-93\%) within 300 min and upper times values give the complete conversion in the presence of $\mathrm{SO}_{2}$.

The abovementioned results encourage us to investigate the SCR performance of the most active solids regarding their tolerance of $\mathrm{SO}_{2}$ and $\mathrm{H}_{2} \mathrm{O}$. When water vapor is introduced, the adsorption of $\mathrm{H}_{2} \mathrm{O}$ on the active metal sites may occur, and the Lewis acid sites might be converted into Brønsted acid sites via bonding of a water molecule, in line with the findings [60]. The literature reports also show that the $\mathrm{SO}_{2}$ might be harmful to the metal active sites in reason of the permanent and irreversible $\mathrm{SO}_{2}$ adsorption on the metal, besides the competitive adsorption of $\mathrm{NO}_{\mathrm{x}}, \mathrm{CO}$ and $\mathrm{SO}_{2}$ for the active sites [15,56]. Another fact is that $\mathrm{SO}_{2}$ addition may form elemental sulfur, which probably could cover the active metal surface and block the pores causing damage in the catalyst structure $[8,61]$. Therefore, the NiNT deactivation is observed, when the catalyst is poisoned by $\mathrm{SO}_{2}$ (Figure $7 \mathrm{~b}$ ). Besides, it can be inferred that the adsorption ability of $\mathrm{SO}_{2}$ on the Lewis and Brønsted sites, i.e., formed by water, is much higher than that of $\mathrm{NO}_{x}$ and $\mathrm{CO}$; hence $\mathrm{SO}_{2}$ may not occupy the Ni sites of NiNT leading to the catalyst deactivation. Contrary, CoNT and PtNT are resistant against $\mathrm{SO}_{2}$ deactivation, under the same conditions during the catalytic run. These results confirm that incorporation of Co on the NTs layered structure and the dispersion of $\mathrm{Pt}$ on the NTs surface provide active redox sites to the reaction. However, the well-dispersed Co in low interaction with the NTs support may provide unstable sites during the reaction, resulting in the facile poison by both water vapor and $\mathrm{SO}_{2}$ (Figure $7 \mathrm{~b}$ ) with the consequent limit catalytic performance of the CoNT catalyst.

PtNT catalyst has the best performance in CO-SCR at low temperatures, when water is introduced in $200 \mathrm{~min}$ and then cut off, and simultaneously, $\mathrm{SO}_{2}$ is introduced in the reaction whilst NiNT has low resistance against sulfur poisoning (Figure 7b). It can be understood that both NiNT and CoNT are extremely sensitive to the poisons, implying that the catalytic activity declined due to the lattice $\mathrm{Co}^{2+}$ ions oxidation by $\mathrm{SO}_{2}$ into the NTs structure and sulfur decomposition on $\mathrm{Ni}^{2+}$ sites, as well.

Our results show the reaction occurrence at lower temperature, most probably due to the formation of surface isocyanate species (NCO) on the decoration of the Pt nanoparticles on the NTs structure already at $150{ }^{\circ} \mathrm{C}$. In the meantime, the PtNT catalyst undergoes the complete $\mathrm{NO}_{x}$ conversion above to $200^{\circ} \mathrm{C}$, due to the lower acidity and reduction of the $\mathrm{Pt}^{2+}$ sites compared to NiNT and CoNT. It is worth noticing that PtNT reduction occurs in two steps, $140-280$ and $280-470{ }^{\circ} \mathrm{C}$, respectively, attributed to the reduction of $\mathrm{PtO}_{\mathrm{x}}$ species (TPR and XPS results). 
When correlating with the catalytic behavior of the PtNT, one can observe that the lower conversion of NiNT may be a result of the sintering of the Ni nanoparticles and preferential CO decomposition [4] during the reaction. On the contrary, an enhancement of the PtNT activity is seen at $200{ }^{\circ} \mathrm{C}$ towards the poisons due to the Pt species stability into the NT structure, as further seen by spent catalysts characterizations. In comparison with the other solids, PtNT achieves the intrinsic rate and turnover frequency values of $3 \times 10^{-10} \mathrm{~mol} \mathrm{~m}^{-2} \mathrm{~s}^{-1}$ and $0.56 \mathrm{~h}^{-1}$, respectively, after $6 \mathrm{~h}$ of exposure to the $\mathrm{SO}_{2}$ and water vapor poisons. This illustrates the influence of the Pt species in the NTs resulting in a suitable catalyst for CO-SCR reaction.

\subsection{Spent Catalysts Characterizations}

The catalysts are characterized again, after the reaction to evaluate the structural and morphological changes that they could undergo.

\subsubsection{Structural Features of the Spent Solids}

The XRD patterns of the spent catalysts tested at $250{ }^{\circ} \mathrm{C}$ after $600 \mathrm{~min}$ of CO-SCR reaction are depicted in Figure 8a.
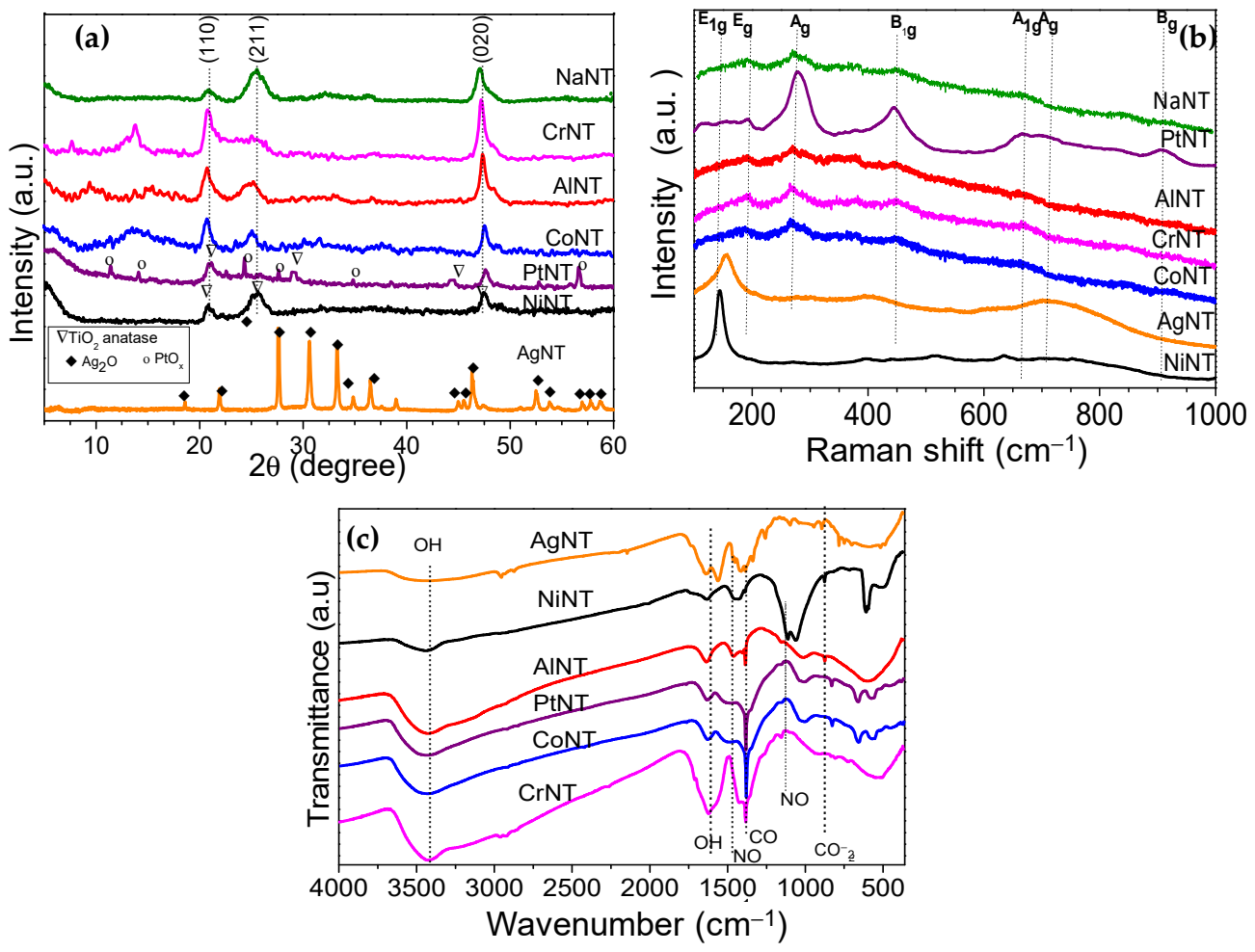

Figure 8. Spent characterizations of the titanate nanotubes catalysts: (a) XRD patterns, (b) Raman and (c) FTIR spectra. Reaction conditions: amount of the catalyst, $0.15 \mathrm{~g}$; reaction gas mixture, $500 \mathrm{ppm}$ of NO, $1000 \mathrm{ppm}$ of CO and balance in He; flow rate, $80 \mathrm{~mL} \mathrm{~min}^{-1}$; space velocity, $48,000 \mathrm{~h}^{-1}$ at $250{ }^{\circ} \mathrm{C}$ for $600 \mathrm{~min}$.

Except for AgNT, all catalysts exhibit a typical NTs structure with characteristic diffraction (100), (211) and (020) planes of the monoclinic $\mathrm{Na}_{2} \mathrm{Ti}_{3} \mathrm{O}_{7}$ structure. As the intensity and position of the diffraction peaks of the $\mathrm{Na}_{2} \mathrm{Ti}_{3} \mathrm{O}_{7}$ phase in, the spent NTs have no obvious differences compared to that observed with the fresh catalysts (Figure 1a), and it can be suggested that their structure remains after the catalytic test due to the mild reaction conditions used. Some perturbations are clearly visible in the XRD peak positions as those of the (110) and (211) reflections in the CrNT, AgNT and AlNT spent catalysts, owing to the deposition of carbon species on solid surface after the catalytic test. 
Additionally, the CoNT has the diffraction peaks displaced to lower $2 \theta$ regions indicating that the perturbation of the NTs structure and the formation of extra framework Co species, as well. Moreover, the peaks of the $\gamma-\mathrm{AlOOH}$ and $\alpha-\mathrm{CoOOH}$ phases do not remain visible, which is all indicative of the leaching of these phases after the reaction. It is noted that the intensity of the characteristic peaks of the cubic $\mathrm{Ag}_{2} \mathrm{O}$ is present in the stable $\mathrm{AgNT}$ structure. In the case of the NiNT, peaks from the NTs phase along with $\mathrm{TiO}_{2}$ anatase are seen. Moreover, there is no Ni species visible since the intercalation of these species in the NTs interlayer region remains. Moreover, the $\mathrm{TiO}_{2}$ anatase phase is produced by the partial calcination of the solid, as a result of both intercalated and surface $\mathrm{Ni}^{2+}$ species with $\mathrm{Ti}^{3+}$ interactions under the reaction conditions evaluated. For spent PtNT, certain features of the trititanate and $\mathrm{TiO}_{2}$ anatase phases are seen in the XRD pattern besides some narrow peaks associated with the $\mathrm{PtO}_{x}$ species. This suggests that a high fraction of $\mathrm{Pt}^{2+}$ species is exposed after the catalytic test.

Regarding the $\mathrm{NO}_{x}$ conversions being in the sequence of $\mathrm{PtNT}>\mathrm{NiNT}>\mathrm{CoNT}>$ CrAlNT $\sim$ AlNT $>\mathrm{NaNT}$ at $250^{\circ} \mathrm{C}$ (Figure 6), it suggested that the metals such as Ni, Pt and $\mathrm{Co}$ are active components remains in the NTs, which results in the maintenance of their structure. Conversely, $\mathrm{Cr}, \mathrm{Ag}, \mathrm{Na}$ and AlNT have poor catalytic performance, and this may be ascribed to lesser accessibility of these species to the reactants at $250{ }^{\circ} \mathrm{C}$, despite their structure being retained after the reaction.

The Raman spectra of metal catalysts are examined after the CO-SCR reaction. Figure $8 \mathrm{~b}$ depicts the spectra recorded after using the samples for $1 \mathrm{~h}$ at $250^{\circ} \mathrm{C}$. The NaNT, AlNT, CoNT, PtNT and CrNT spectra exhibit broad prominent bands at around 236, 353, 500, 514 (shoulder), 669 (shoulder), 681, 815, 850 and $958 \mathrm{~cm}^{-1}$. By comparison with Figure $1 \mathrm{~b}$, some of these bands are closely related to the $276(\mathrm{Ag}), 445$ (B1g), 656 (A1g), 696 (Ag) and $908(\mathrm{Bg}) \mathrm{cm}^{-1}$ vibrational modes of the trititanate structure, in line with the literature reports $[4,25]$. The similarity of the NiNT and AgNT spectra indicates that trititanate structures would be coexisting with the $\mathrm{TiO}_{2}$ anatase ones with the main Raman modes at 144, 402 and $650 \mathrm{~cm}^{-1}$, in line with the findings [62]. Specifically, for AgNT, the Ag-O vibration from $\mathrm{Ag}_{2} \mathrm{O}$ phase at around 561, 700 and $1010 \mathrm{~cm}^{-1}$ still detected [32]. In the case of NiNT, the bands are broader and more intense than those of AgNT, and thus, the modes ascribed to be from $\mathrm{TiO}_{2}$ anatase stretching are more evident. These results confirm the $\mathrm{XRD}$ results that demonstrate that the structures of the NaNT, AlNT, CoNT, PtNT and CrNT solids are not affected after the catalytic test and ascertain the catalytic performance of these solids due to their stability due to the mild conditions used during the reaction. However, the vibrational modes of the trititanate structure are vanished from the AgNT and NiNT either causing the phase transformations or forming organic other adsorbed compounds. This is further confirmed by FTIR and SEM-EDS analyses.

FTIR spectra of the solids are also examined after the reaction (Figure 8b). All spent solids are dominated by the significant absorptions of $\mathrm{OH}$ vibrations at about 3600 and $1640 \mathrm{~cm}^{-1}$ from the stretching and bending vibrations of the $\mathrm{OH}$ groups, respectively. This assignment may be due to the physically adsorbed water and the structural $\mathrm{OH}$ groups [13]. Several bands are seen in the $3000-1000 \mathrm{~cm}^{-1}$ region in comparison with the spectra of the fresh solids (Figure 1c).

The weak bands at around $1585 \mathrm{~cm}^{-1}$ arises as $v$ NO from bidentate nitrates, which results in the $\mathrm{NO}_{\mathrm{x}}$ decomposition $[6,13]$. The bands at 1060,1347 and $1557 \mathrm{~cm}^{-1}$ are ascribable to the carbonates $v_{a s}\left(\mathrm{CO}_{2}{ }^{-}\right)$from $\mathrm{CO}$ dissociation onto the surface as a consequence of the methanation or Water Gas Shift (WGS) reactions [4,6]. The low intensity of these bands evidences a small amount of carbonates adsorbed on solid surface. The formation of carbon species deposits on AgNT, CrNT and AlNT spent catalysts is likely. Such reactions are possibly related to the deactivation behavior of these solids. Additionally, the nitrite adsorbed species arising from the oxidation of $\mathrm{NO}$ on PtNT and NiNT sites to $\mathrm{NO}_{2}$ are visible at 1292 and $1255 \mathrm{~cm}^{-1}\left(v_{\text {asym }} \mathrm{NO}_{2}\right)$ and concomitantly with the 1030-1000 $\mathrm{cm}^{-1}$ range $\left(v_{\text {sym }} \mathrm{NO}_{2}\right)$, as well. The bands associated with the $\left(v_{\text {asym }} \mathrm{NO}_{3}\right)$ are depicted at 1320 and $1420-1000 \mathrm{~cm}^{-1}$ from nitrates formed during the reaction [63]. These absorption bands 
are observable over NiNT and PtNT samples, indicating the preferential adsorption of $\mathrm{NO}_{\mathrm{x}}$ on these solids. As found elsewhere, the nitrates species are seen at around 1418, 1307, $1020 \mathrm{~cm}^{-1}$ whereas the chelates are visible at around $1552 \mathrm{~cm}^{-1}$ when adsorbing $\mathrm{NO}_{\mathrm{x}}$ at around $350{ }^{\circ} \mathrm{C}$ on Pt-based samples $[6,63]$.

\subsubsection{Morphological Features of the Spent Solids}

SEM-EDS images confirm observations showing the morphological evolution by poisoning of the CoNT, NiNT and PtNT solids. The morphologies of the spent solids (Figures 9-11) are distinct from those of fresh catalysts (Figures 2b and 3f,g). Accordingly, the fresh CoNT exhibits a slight aggregation of the nanotubes forming a rough surface [4], before the reaction. Instead, more aggregated titanates nanotubes particles morphology is clearly visible when CoNT is used at $250{ }^{\circ} \mathrm{C}$ for $600 \mathrm{~min}$. in the presence of $\mathrm{SO}_{2}$ and water vapor poisons, as shown in Figure 9 through SEM image. Moreover, EDS mapping illustrates a well dispersion of the oxygen, titanium and cobalt, elements of ca. 55.6, 31.7, $0.3 \%$, respectively. Moreover, an enormous amount of sulfur deposits of ca. $12.4 \%$ is seen on solid surface. As evidenced by the appearance of a significant amount of sulfur and no carbon, the cobalt species are easily oxidized in the reaction media. The sulfur deposits on surface favor the inaccessibility to the Co active sites, which is reasonably responsible for the catalytic activity in CO-SCR. Moreover, the sulfur deposition does not significantly affect the tubular structure, and one can see the Co nanoparticles having sizes in the 1-5 nm range intercalated (decorated) on the nanotubes, as illustrated by TEM image. Hence, low $\mathrm{SO}_{2}$ tolerance is the leading cause of the deactivation of the CoNT catalyst. The cobalt is well known as very smooth oxidant for $\mathrm{CO}$ involved reactions [4], and thus, the oxidation of the $\mathrm{Co}^{2+}$ species along with the sulfur formed during the experiments impedes either $\mathrm{NO}_{x}$ or $\mathrm{CO}$ adsorption on the active sites resulting in the deactivation of the solid.

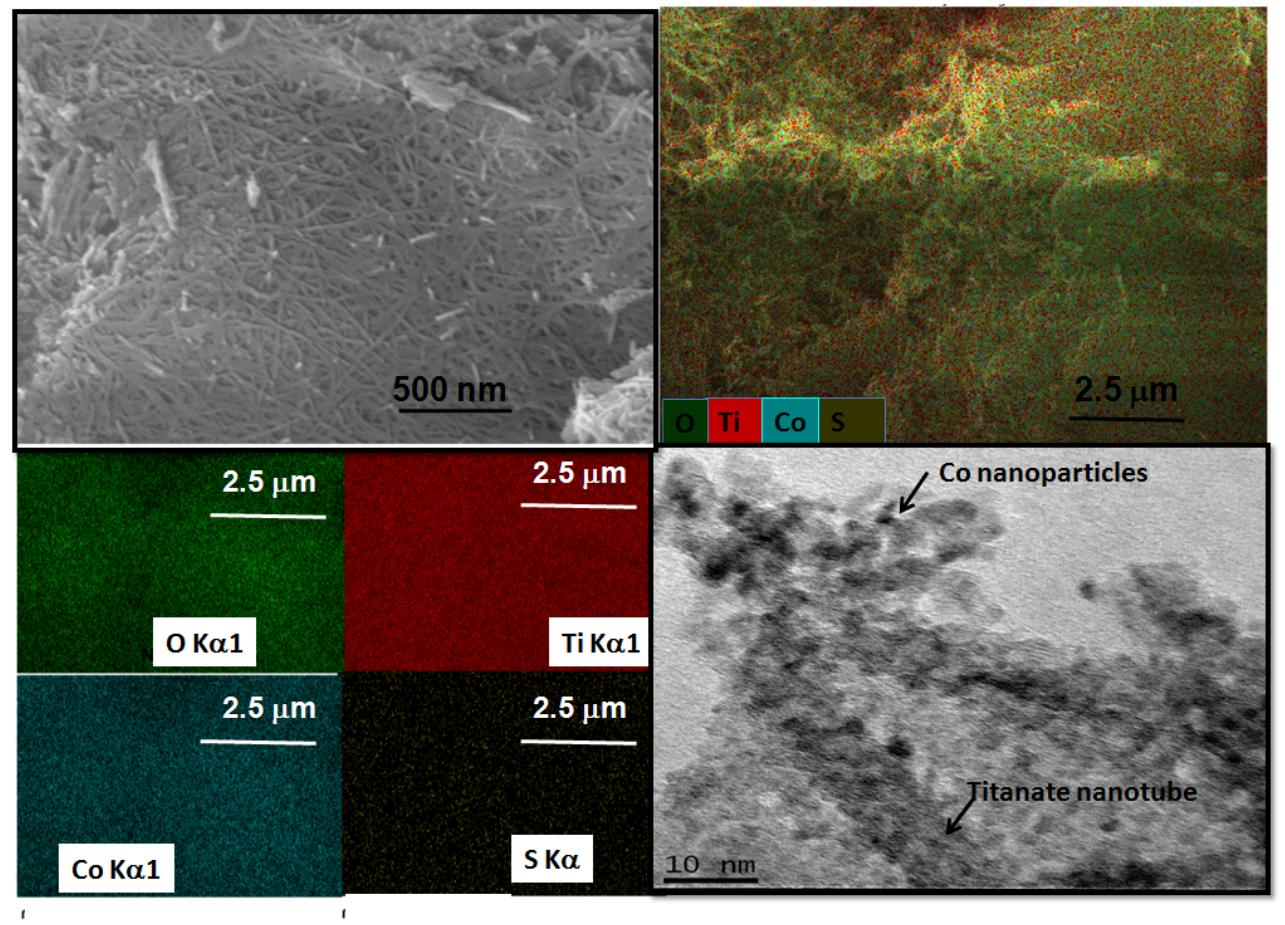

Figure 9. SEM-EDS and TEM images of CoNT spent titanate nanotubes catalyst characterizations. Reaction conditions: amount of the catalyst, $0.15 \mathrm{~g}$; reaction gas mixture, $500 \mathrm{ppm}$ of NO, $1000 \mathrm{ppm}$ of $\mathrm{CO}$ and balance in $\mathrm{He}$; flow rate, $80 \mathrm{~mL} \cdot \mathrm{min}^{-1}$; space velocity, 48,000 $\mathrm{h}^{-1}$. Either $10 \mathrm{wt} \%(v / v)$ of water vapor or $50 \mathrm{ppm}$ of $\mathrm{SO}_{2}$ (or both) was used during the reaction at $250{ }^{\circ} \mathrm{C}$ for $6 \mathrm{~h}$. 


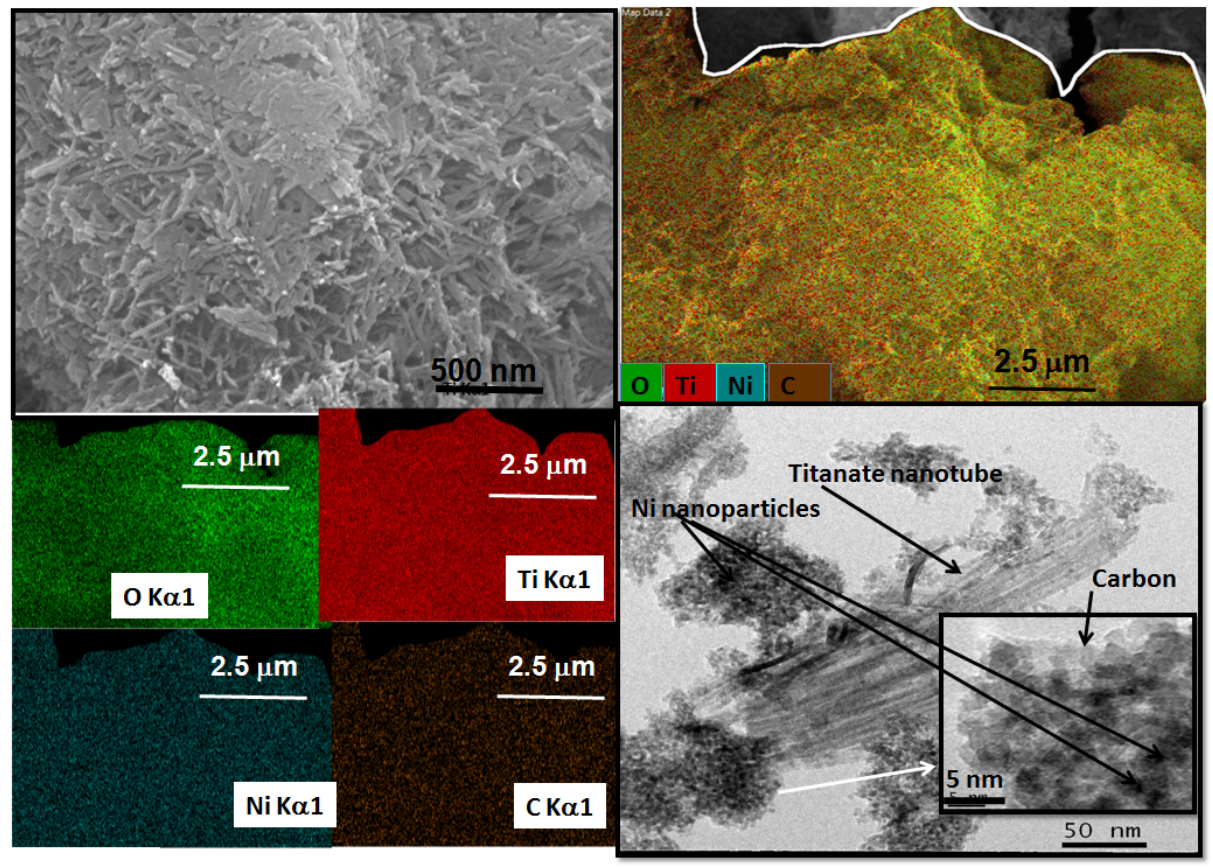

Figure 10. SEM-EDS and TEM images of NiNT spent titanate nanotubes catalyst characterizations. Reaction conditions: amount of the catalyst, 0.15 g; reaction gas mixture, 500 ppm of NO, 1000 ppm of $\mathrm{CO}$ and balance in $\mathrm{He}$; flow rate, $80 \mathrm{~mL} \cdot \mathrm{min}^{-1}$; space velocity, 48,000 $\mathrm{h}^{-1}$. Either $10 \mathrm{wt} \%(v / v)$ of water vapor or $50 \mathrm{ppm}$ of $\mathrm{SO}_{2}$ (or both) was used during the reaction at $250{ }^{\circ} \mathrm{C}$ for $6 \mathrm{~h}$.

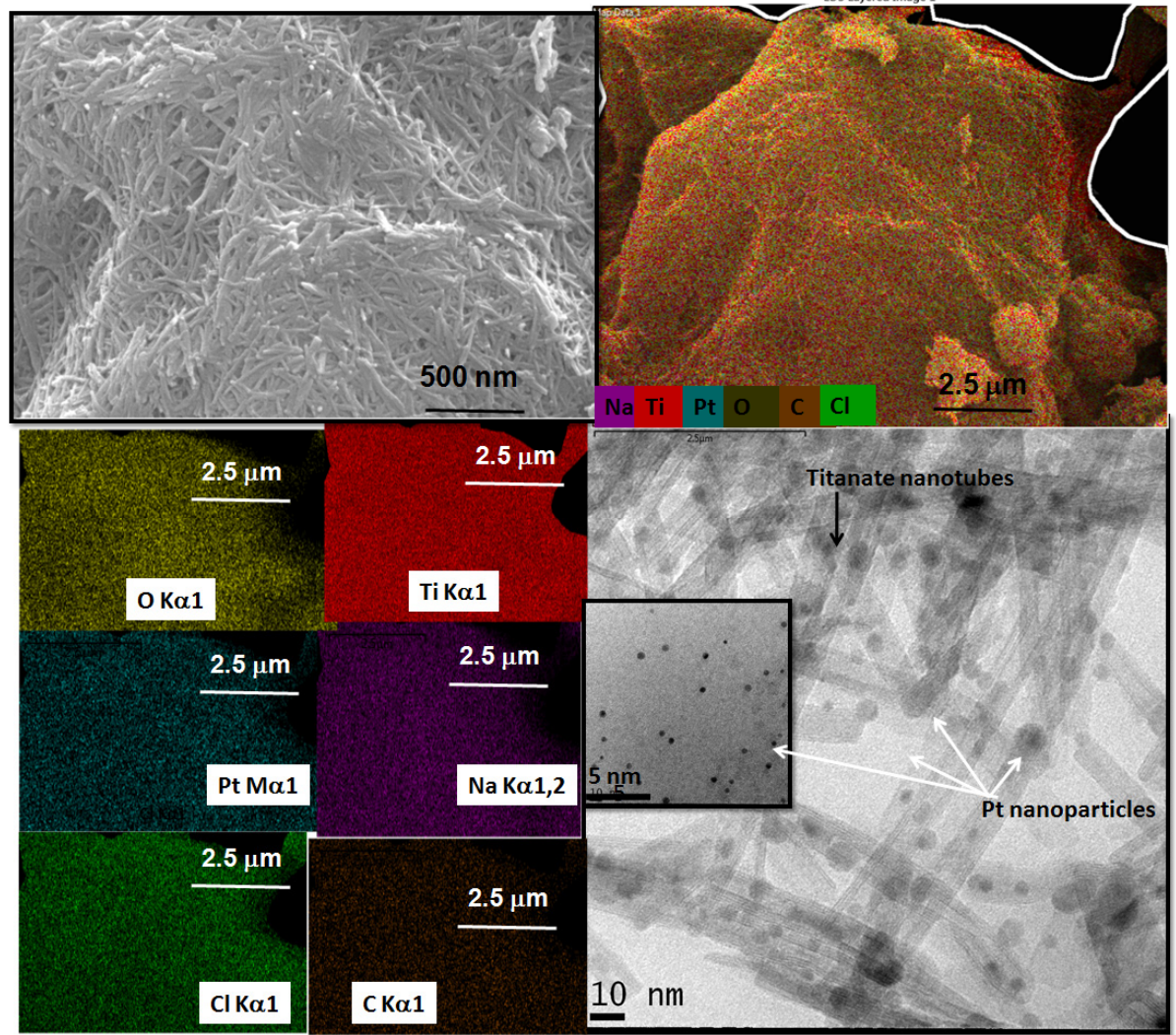

Figure 11. SEM-EDS and TEM images of PtNT spent titanate nanotubes catalyst characterizations. Reaction conditions: amount of the catalyst, $0.15 \mathrm{~g}$; reaction gas mixture, $500 \mathrm{ppm}$ of NO, $1000 \mathrm{ppm}$ of $\mathrm{CO}$ and balance in $\mathrm{He}$; flow rate, $80 \mathrm{~mL} \cdot \mathrm{min}^{-1}$; space velocity, 48,000 $\mathrm{h}^{-1}$. Either $10 \mathrm{wt} \%(v / v)$ of water vapor or $50 \mathrm{ppm}$ of $\mathrm{SO}_{2}$ (or both) was used during the reaction at $250{ }^{\circ} \mathrm{C}$ for $6 \mathrm{~h}$. 
In the case of spent NiNT (Figure 10), unlike CoNT, on which $\mathrm{NO}_{\mathrm{x}}$ conversion is decreased during the poisoning experiments, SEM images illustrate that the titanate nanotubes morphology remains with the tubes entangled forming a dense plate, in line with Raman and XRD results. For further ensuring the uniform dispersion of each element in the spent catalysts, the EDS elemental mapping images indicate that each element (e.g., $\mathrm{Na}, \mathrm{Ti}$ and $\mathrm{O}$ ) is uniformly distributed throughout the solid surface. Moreover, $\mathrm{Ni}$ particles are clearly visible on solid surface with $\mathrm{C}$ coming from the $\mathrm{CO}$ decomposition parallel reactions on metallic Ni nanoparticles during the reaction [4]. Moreover, the sulfur observed by EDS is $0.0 \%$ on NiNT surface. Previous studies have demonstrated the Ni ability of forming coke under relatively mild condition, when $\mathrm{CO}$ is present in catalytic reactions $[4,63]$. Noteworthy, TEM image depicts the tubular morphology of the titanate nanotubes along with a bundle of Ni nanoparticles. Indeed, these nanoparticles of about 1-10 $\mathrm{nm}$ remain strongly adhered on the surface of the tubes possessing uniform diameters of around 4-50 nm. Moreover, carbon species around the Ni nanoparticles are observable throught the HRTEM images, which could be indicative of the presence of generous carbon deposition, which accords to FTIR results. Thus, the performance of the NiNT catalyst in the SCR-CO reaction (Figure 6) is due to the Ni nanoparticles, but the modest performance is mainly due to the carbon deposits on solid surface and sintering of Ni particles, as well.

To further investigate the stability of PtNT towards the CO-SCR reaction and correlate its structural and morphological features to justify its better performance in the reaction, SEM-EDS and TEM images are performed after the poisoning experiments. The SEM micrograph of spent PtNT (Figure 11) suggests that the morphology of the sample is not altered, after the reaction with the appearance of the entangled nanotubes. Through EDS analyses, $\mathrm{Pt}$ nanoparticles as $\mathrm{PtO}_{\mathrm{x}}$ and $\mathrm{Pt}$-chlorinated species are homogeneously dispersed on the NT surface. Moreover, traces of $\mathrm{Na}$ appear as a result of the remaining $\mathrm{Na}_{2} \mathrm{Ti}_{3} \mathrm{O}_{7}$ phase concomitantly with anatase $\mathrm{TiO}_{2}$ presence while $\mathrm{Cl}$ comes from the chlorinated $\mathrm{Pt}$ species. The HRTEM micrograph somewhat evidences the tubular morphology maintenance with the dark dots corresponding to strikingly dispersion Pt nanoparticles on the external surface of the tubes. These particles are indeed smaller, e.g., 1-5 nm (Figure 11 included) than those NiNT, as expected for Pt-supported based samples.

\section{Conclusions}

Titanate nanotubes containing metals were prepared with the assistance of the ion exchange and impregnation procedures. The structural and compositional characterizations through Raman, FTIR spectroscopy, XRD and HRTEM and SEM-EDS analyses revealed that the sodium from $\mathrm{Na}_{2} \mathrm{Ti}_{3} \mathrm{O}_{7}$ structure was replaced by the $\mathrm{Co}, \mathrm{Pt}, \mathrm{Ni}, \mathrm{Al}$ and $\mathrm{Cr}$ ions in the NTs interlayer regions. Contrary, Ag ions were entirely deposited on NTs surface forming $\mathrm{Ag}_{2} \mathrm{O}$ phase. Besides, the oxy hydroxides of $\mathrm{Al}, \mathrm{Ni}, \mathrm{Co}$ and $\mathrm{Cr}$ were observed as extra framework phases along with Pt oxyhydroxides and Pt-chlorinated species.

The $\mathrm{Ni}, \mathrm{Co}$ and $\mathrm{Pt}$ species had important implications on the catalytic performance of the solids by improving the $\mathrm{NO}_{x}$ conversion, but $\mathrm{Al}, \mathrm{Cr}$ and $\mathrm{Ag}$ species contributed to their modest performance in the $\mathrm{NO}_{\mathrm{x}}$ conversion through CO-SCR reaction at distinct temperatures. The catalytic activity of CoNT, NiNT and PtNT catalysts was more stable in the $\mathrm{CO}-\mathrm{SCR}$ reaction towards the water vapor and $\mathrm{SO}_{2}$ poisons with the former catalyst having moderate conversions. The Co species in CoNT nanotubes showed low $\mathrm{NO}_{x}$ conversions during the poisoning runs; most of the exposed Co nanoparticles catalyze the oxidation reactions, and sulfur deposition on CoNT surface provoked its deactivation. The presence of severe carbonaceous deposition on the NiNT revealed the low stability of the catalyst. On the other hand, intimate synergism between the Pt nanoparticles and the titanate nanotubes structured were considered to be one of the reasons for the superiority of PtNT and in the CO-SCR reaction towards $\mathrm{SO}_{2}$ and water vapor poisons. 
Author Contributions: Conceptualization and supervision, A.C.O.; methodology, J.V.C.d.C., G.M., S.T.-C., C.L.L. and J.M.S.; formal analysis, B.C.V., A.C.O., E.R.-A. and E.R.-C.; investigation, C.L.L., A.M.S.S., L.N.C., A.G., M.S. and B.C.V.; data curation and visualization R.L., A.C.O., S.T.-C. and E.R.-C.; writing-original draft preparation, E.R.-C. and A.C.O.; writing-review and editing, A.C.O., B.C.V., E.R.-C. and E.R.-A. All authors have read and agreed to the published version of the manuscript.

Funding: This research was supported by the CNPq Grant (406629/2018-8) and Pertobras (Física do Petróleo em Meios Porosos, Number: F0185). Authors thank to project RTI2018-099668-BC22 of Ministerio de Ciencia, Innovación y Universidades, and project UMA18-FEDERJA-126 of Junta de Andalucía and FEDER Funds.

Institutional Review Board Statement: Not applicable.

Informed Consent Statement: Not applicable.

Data Availability Statement: The data presented in this study are available on request from the corresponding author.

Acknowledgments: J.V.C.d.C. acknowledges CNPq for the scholarship. The authors are thankful to CETENE and Central Analitica da UFC for some characterization results. We acknowledge Samuel Tehuacanero Núñez, and Jesús Arenas-Alatorre from LCM IFUNAM for the comments and support in the TEM images. R.S.A. is acknowledged by the CO-SCR experiments assistance.

Conflicts of Interest: The authors declare no conflict of interest.

\section{Appendix A}

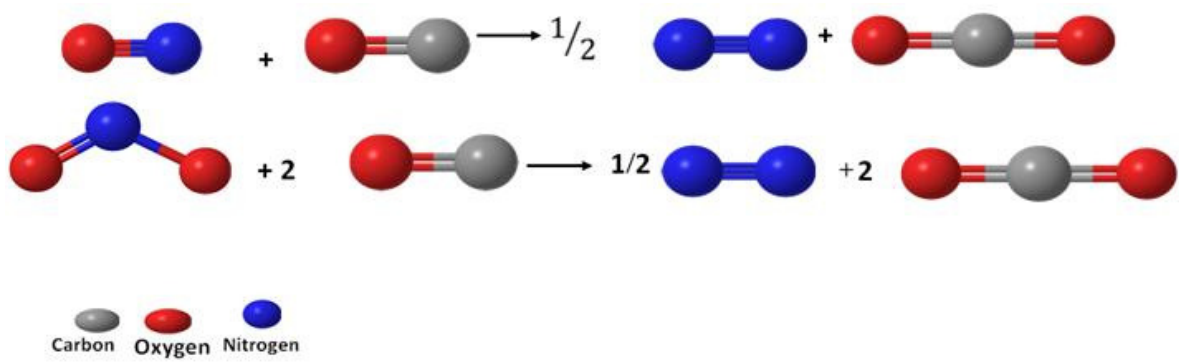

Figure A1. Schematic representation of the reactions that occur during CO-SCR reaction.

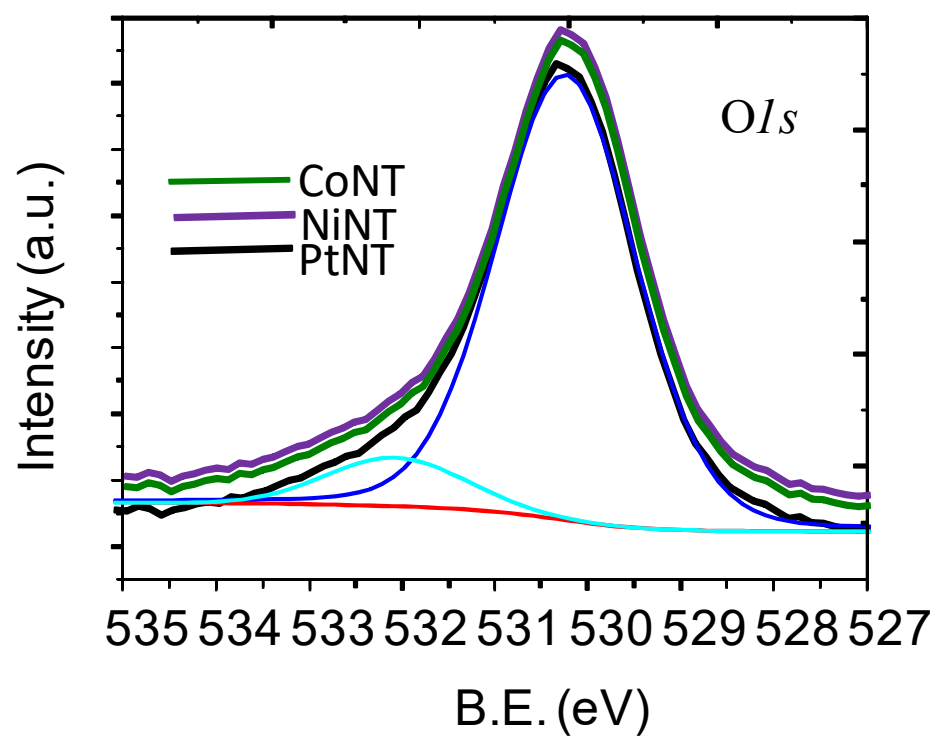

Figure A2. O 1s core level XPS spectra for fresh titanate nanotubes. 


\section{References}

1. References Pisarek, M.; Kędzierzawski, P.; Andrzejczuk, M.; Hołdyński, M.; Mikołajczuk-Zychora, A.; Borodziński, A.; JanikCzachor, $\mathrm{M}$. $\mathrm{TiO}_{2}$ Nanotubes with Pt and Pd Nanoparticles as Catalysts for Electro-Oxidation of Formic Acid. Materials 2020, 13, 1195. [CrossRef]

2. Santos, N.M.; Rocha, J.M.; Matos, J.M.; Ferreira, O.P.; Filho, J.M.; Viana, B.C.; Oliveira, A.C. Metal cations intercalated titanate nanotubes as catalysts for $\alpha, \beta$ unsaturated esters production. Appl. Catal. A Gen. 2013, 454, 74-80. [CrossRef]

3. Smith, Y.R.; Ray, R.S.; Carlson, K.; Sarma, B.; Misra, M. Self-Ordered Titanium Dioxide Nanotube Arrays: Anodic Synthesis and Their Photo/Electro-Catalytic Applications. Materials 2013, 6, 2892-2957. [CrossRef] [PubMed]

4. Coelho, D.C.; Oliveira, A.C.; Filho, J.M.; Oliveira, A.C.; Lucredio, A.F.; Assaf, E.M.; Rodríguez-Castellón, E. Effect of the active metal on the catalytic activity of the titanate nanotubes for dry reforming of methane. Chem. Eng. J. 2016, 290, 438-453. [CrossRef]

5. Aguilar-Romero, M.; Camposeco, R.; Castillo, S.; Marín, J.; Rodríguez-González, V.; García-Serrano, L.A.; Mejía-Centeno, I. Acidity, surface species, and catalytic activity study on V2O5-WO3/TiO2 nanotube catalysts for selective NO reduction by NH3. Fuel 2017, 198, 123-133. [CrossRef]

6. Oton, L.F.; Oliveira, A.C.; Araujo, J.C.S.; Araujo, R.S.; de Sousa, F.F.; Saraiva, G.D.; Lang, R.; Otubo, L.; Duarte, G.C.S.; Campos, A. Selective catalytic reduction of NOx by CO (CO-SCR) over metal-supported nanoparticles dispersed on porous alumina. Adv. Powder Technol. 2020, 31, 464-476. [CrossRef]

7. Zhang, Y.; Yue, X.; Huang, T.; Shen, K.; Lu, B. In Situ DRIFTS Studies of NH3-SCR Mechanism over V2O5-CeO2/TiO2-ZrO2 Catalysts for Selective Catalytic Reduction of NOx. Materials 2018, 11, 1307. [CrossRef]

8. Pappas, D.K.; Boningari, T.; Boolch, P.; Smirniotis, P.G. Novel manganese oxide confined interweaved titania nanotubes for the low-temperature selective catalytic reduction (SCR) of $\mathrm{NO}_{x}$ by $\mathrm{NH}_{3}$. J. Catal. 2016, 334, 1-13. [CrossRef]

9. Wang, H.; Wang, P.; Chen, X.; Wu, Z. Uniformly active phase loaded selective catalytic reduction catalysts (V2O5/TNTs) with superior alkaline resistance performance. J. Hazard. Mater. 2017, 324, 507-515. [CrossRef]

10. Boningari, T.; Pappas, D.K.; Smirniotis, P.G. Metal oxide-confined interweaved titania nanotubes M/TNT (M = Mn, Cu, Ce, Fe, V, $\mathrm{Cr}$, and $\mathrm{Co}$ ) for the selective catalytic reduction of NOx in the presence of excess oxygen. J. Catal. 2018, 365, 320-333. [CrossRef]

11. Pal, N.; Murray, E.P. Dense LaSrMnO3 composite electrodes for NOx sensing. Sens. Actuators B Chem. 2018, 256, 351-358. [CrossRef]

12. Zhang, Y.; Wu, P.; Zhuang, K.; Shen, K.; Wang, S.; Guo, W. Effect of $\mathrm{SO}_{2}$ on the Selective Catalytic Reduction of $\mathrm{NO}_{\mathrm{x}}$ over $\mathrm{V}_{2} \mathrm{O}_{5}-\mathrm{CeO}_{2} / \mathrm{TiO}_{2}-\mathrm{ZrO}_{2}$ Catalysts. Materials 2019, 12, 2534. [CrossRef]

13. Nascimento, J.P.S.; Oliveira, A.C.; Araujo, J.C.S.; de Sousa, F.F.; Saraiva, G.D.; Rodríguez-Aguado, E.; Rodríguez-Castellón, E. Combined promoting effect of molybdenum on the bimetallic $\mathrm{Al}_{2} \mathrm{O}_{3}-\mathrm{La}_{2} \mathrm{O}_{3}$ catalysts for $\mathrm{NO}_{x}$ reduction by CO. Fuel 2020, 275, 11787. [CrossRef]

14. Zheng, Y.; Liu, Y.; Harold, M.P.; Luss, D. LNT-SCR dual-layer catalysts optimized for lean NOx reduction by H2 and CO. Appl. Catal. B Environ. 2014, 148-149, 311-321. [CrossRef]

15. Mrada, R.; Aissat, A.; Cousin, R.; Courcot, D.; Siffert, S. Catalysts for $\mathrm{NO}_{\mathrm{x}}$ selective catalytic reduction by hydrocarbons (HC-SCR). Appl. Catal. A Gen. 2015, 504, 542-548. [CrossRef]

16. Dasireddy, V.D.B.C.; Likoz, B. Selective catalytic reduction of $\mathrm{NO}_{\mathrm{x}}$ by $\mathrm{CO}$ over bimetallic transition metals supported by multi-walled carbon nanotubes (MWCNT). Chem. Eng. J. 2017, 326, 886-900. [CrossRef]

17. Sun, P.; Cheng, X.; Lai, Y.; Wang, Z.; Ma, C.; Chang, J. NOx reduction by CO over ASC catalysts in a simulated rotary reactor: Effect of $\mathrm{CO}_{2}, \mathrm{H}_{2} \mathrm{O}$ and $\mathrm{SO}_{2}$. RSC Adv. 2018, 8, 36604-36615. [CrossRef]

18. Jiang, B.; Lin, B.; Li, Z.; Zhao, S.; Chen, Z. Mn/TiO 2 catalysts prepared by ultrasonic spray pyrolysis method for NOx removal in low-temperature SCR reaction. Colloids Surf. A Physicochem. Eng. Asp. 2020, 586, 124210. [CrossRef]

19. Wang, P.; Wang, H.; Chen, X.; Liu, Y.; Weng, X.; Wu, Z. Novel SCR catalyst with superior alkaline resistance performance: Enhanced self-protection originated from modifying protonated titanate nanotubes. J. Mater. Chem. A 2015, 3, 680-690. [CrossRef]

20. Zouzelka, R.; Rathouskya, J. Photocatalytic abatement of NOx pollutants in the air using commercial functional coating with porous morphology. Appl. Catal. B. Environ. 2017, 217, 466-476.

21. Camposeco, R.; Castillo, S.; Nava, N.; Maturano, V.; Zanella, R. Comparison of the Performance of Au, Pt and Rh Nanoparticles Supported on Mn/Alkali Titanate Nanotubes in Formaldehyde Oxidation at Room Temperature. Catal. Lett 2020, 150, 3342-3358.

22. Mejía-Centeno, I.; Castillo, S.; Camposeco, R.; Marín, J.; Fuentes, G.A. Activity and selectivity of $\mathrm{V}_{2} \mathrm{O}_{5} / \mathrm{H}_{2} \mathrm{Ti}_{3} \mathrm{O}_{7}, \mathrm{~V}_{2} \mathrm{O}_{5}-$ $\mathrm{WO}_{3} / \mathrm{H}_{2} \mathrm{Ti}_{3} \mathrm{O}_{7}$ and $\mathrm{Al}_{2} \mathrm{O}_{3} / \mathrm{H}_{2} \mathrm{Ti}_{3} \mathrm{O}_{7}$ model catalysts during the SCR-NO with $\mathrm{NH}_{3}$. Chem. Eng. J. 2015, 264, 873-885. [CrossRef]

23. Chen, X.; Cao, S.; Weng, X.; Wang, H.; Wu, Z. Effects of morphology and structure of titanate supports on the performance of ceria in selective catalytic reduction of NO. Catal. Commun. 2012, 26, 178-182. [CrossRef]

24. Chen, X.; Wang, P.; Fang, P.; Wang, H.; Cen, C.; Zeng, W.; Wu, Z. Design strategies for SCR catalysts with improved N 2 selectivity: The significance of nano-confining effects by titanate nanotubes. Environ. Sci. Nano 2016, 4, 437-447. [CrossRef]

25. Gomes, I.S.; De Carvalho, D.C.; Oliveira, A.C.; Rodríguez-Castellón, E.; Tehuacanero-Cuapa, S.; Freire, P.T.; Filho, J.M.; Saraiva, G.D.; De Sousa, F.F.; Lang, R. On the reasons for deactivation of titanate nanotubes with metals catalysts in the acetalization of glycerol with acetone. Chem. Eng. J. 2018, 334, 1927-1942. [CrossRef]

26. Carvalho, D.C.; Oliveira, A.C.; Ferreira, O.P.; Filho, J.M.; Tehuacanero-Cuapa, S.; Oliveira, A.C. Titanate nanotubes as acid catalysts for acetalization of glycerol with acetone: Influence of the synthesis time and the role of structure on the catalytic performance. Chem. Eng. J. 2017, 313, 1454-1467. [CrossRef] 
27. Zaki, A.H.; Hafiez, M.A.; El Rouby, W.M.A.; El-Dek, S.I.; Farghali, A.A. Novel magnetic stand points in $\mathrm{Na}_{2} \mathrm{Ti}_{3} \mathrm{O}_{7}$ nanotubes. J. Magn. Magn. Mater. 2019, 476, 207-212. [CrossRef]

28. Sun, X.M.; Li, Y.D. Synthesis and Characterization of Ion-Exchangeable Titanate Nanotubes. Chem. A Eur. J. 2003, 9, 2229-2238. [CrossRef]

29. Peng, S.; Zeng, X.; Li, Y. Titanate nanotube modified with different nickel precursors for enhanced Eosin Y-sensitized photocatalytic hydrogen evolution. Int. J. Hydrogen Energy 2015, 40, 6038-6049. [CrossRef]

30. Liu, L.; Zhou, Z.; Peng, C. Sonochemical intercalation synthesis of nano-nickel oxyhydroxide: Structure and electrochemical properties. Electrochim. Acta 2008, 54, 434-444. [CrossRef]

31. Dou, X.; Hao, W.; Li, X.; Qin, L.; Kang, S.-Z. Ti mesh loaded with Ag "nanobosk": A highly sensitive Raman sensing platform for trace norfloxacin in water. Sens. Actuators B Chem. 2019, 283, 163-171. [CrossRef]

32. Wei, J.; Lei, Y.; Ji, H.; Cheng, J.; Hou, H.; Zheng, Z. Controlled in situ fabrication of $\mathrm{Ag}_{2} \mathrm{O} / \mathrm{AgO}$ thin films by a dry chemical route at room temperature for hybrid solar cells. Dalton Trans. 2014, 43, 11333-11338. [CrossRef]

33. Waterhouse, G.I.N.; Bowmaker, G.A.; Metson, J.B. The thermal decomposition of silver (I, III) oxide: A combined XRD, FT-IR and Raman spectroscopic study. Phys. Chem. Chem. Phys. 2001, 3, 3838-3845. [CrossRef]

34. Kanazawa, Y.; Itadani, A.; Hashimoto, H.; Uematsu, K.; Toda, K.; Sato, M. Room temperature adsorption of propene and propane on copper ions distributed in titanate nanotubes. Appl. Surf. Sci. 2019, 483, 642-651. [CrossRef]

35. Vranješa, M.; Jakovljević, J.K.; Milošević, M.; Ćirić-Marjanović, G.; Stoiljković, M.; Konstantinović, Z.; Pavlović, V.; Milivojević, D.; Šaponji, Z. Hydrothermal synthesis of $\mathrm{Mn}^{2+}$ doped titanate nanotubes: Investigation of their structure and room temperature ferromagnetic behavior. Solid State Sci. 2019, 94, 155-161. [CrossRef]

36. Mariotto, G.; Cazzinelli, E.; Carturan, G.; Di Maggio, R.; Scardi, P. Raman and X-ray diffraction study of boehmite gels and their transformation to $\alpha$ - or $\beta$-alumina. J. Solid State Chem. 1990, 86, 263-274. [CrossRef]

37. Moshaw, T.M.M.; Damilol, J.M.; Abdulhakeem, M.; Julienm, B.; Dangbegnon, K.; Manyala, N. High electrochemical performance of hybrid cobalt oxyhydroxide/nickel foam graphene. J. Colloid Interface Sci. 2016, 484, 77-85.

38. Yang, J.J.; Martens, W.N.; Frost, R.L. Transition of chromium oxyhydroxide nanomaterials to chromium oxide: A hot-stage Raman spectroscopic study. J. Raman Spectrosc. 2010, 42, 1142-1146. [CrossRef]

39. Connor, P.A.; Dobson, K.D.; McQuillan, A.J. Infrared Spectroscopy of the $\mathrm{TiO}_{2} /$ Aqueous Solution Interface. Langmuir 1999, 15, 2402-2408. [CrossRef]

40. Alban, L.; Monteiro, W.F.; Diz, F.M.; Miranda, G.M.; Scheid, C.M.; Zotti, E.R.; Morrone, F.B.; Ligabue, R. New quercetin-coated titanate nanotubes and their radio sensitization effect on human bladder cancer. Mater. Sci. Eng. C 2020, 110, 110662. [CrossRef]

41. Egerton, T.A.; Harris, E.; Lawson, E.J.; Mileband, B.; Rowlands, C.C. An EPR study of diuusion of chromium into rutile. Phys. Chem. Chem. Phys. 2000, 2, 3275-3281. [CrossRef]

42. Marć, M.; Najder-Kozdrowska, L.; Guskos, N.; Żołnierkiewicz, G.; Montero, A.M.; Dudek, M.R. The Use of Ultra-Small Fe ${ }_{3} \mathrm{O}_{4}$ Magnetic Nanoparticles for Hydrothermal Synthesis of $\mathrm{Fe}^{3+}$ Doped Titanate Nanotubes. Materials 2020, 13, 4612. [CrossRef]

43. Zheng, P.; Zhou, W.; Wang, Y.; Ren, D.; Zhao, J.; Guo, S. N-doped graphene-wrapped $\mathrm{TiO}_{2}$ nanotubes with stable surface Ti ${ }^{3+}$ for visible-light photocatalysis. Appl. Surf. Sci. 2020, 512, 144549. [CrossRef]

44. Souza, J.S.; Krambrock, K.; Pinheiro, M.V.B.; Ando, R.A.; Guha, S.; Alves, W.A. Visible-light photocatalytic activity of NH 4 NO 3 ion-exchanged nitrogen-doped titanate and $\mathrm{TiO}_{2}$ nanotubes. J. Mol. Catal. A Chem. 2014, 394, 48-56. [CrossRef]

45. Mandari, K.K.; Kwak, B.S.; Police, A.K.R.; Kang, M. In-situ photo-reduction of silver particles and their SPR effect in enhancing the photocatalytic water splitting of $\mathrm{Ag}_{2} \mathrm{O} / \mathrm{TiO}_{2}$ photocatalysts under solar light irradiation: A case study. Mater. Res. Bull. 2017, 95, 515-524. [CrossRef]

46. Wu, D.; Chen, Y.; Liu, J.; Zhao, X.; Li, A.; Ming, N. Co-Doped Titanate Nanotubes. Appl. Phys. Lett. 2005, 87, 112501. [CrossRef]

47. Pinheiro, A.L.G.; Oliveira, A.P.S.; Sousa, F.F.; Soares, J.M.; Saraiva, G.D.; Oliveira, A.C.; Lang, R. CeFe-Based Bead Nanocomposites as Catalysts for Oxidation of Ethylbenzene Reaction. Catalysts 2018, 8, 495. [CrossRef]

48. Ma, X.; Wu, J.; Xu, L.; Zhao, B.; Chen, F. Modulation of Pt species on oxygen vacancies enriched $\mathrm{TiO}_{2}$ via $\mathrm{UV}$ illumination for photocatalytic performance optimization. Colloids Surf. A Physicochem. Eng. Asp. 2020, 586, 124243. [CrossRef]

49. Liu, S.; Liu, J.; Lin, Q.; Xu, S.; Wang, J.; Xu, H.; Chen, Y. Solvent Effects on the Low-Temperature NH3-SCR Activity and Hydrothermal Stability of $\mathrm{WO}_{3} / \mathrm{SiO}_{2} @ C e Z r O x$ Catalyst. ACS Sustain. Chem. Eng. 2020, 8, 13418-13429. [CrossRef]

50. Wang, P.; Gao, S.; Wang, H.; Chen, S.; Chen, X.; Wu, Z. Enhanced dual resistance to alkali metal and phosphate poisoning: Mo modifying vanadium-titanate nanotubes SCR catalyst. Appl. Catal. A Gen. 2018, 561, 68-77. [CrossRef]

51. Yan, S.; Wu, Z.; Xu, Q.; Wang, J.J.; Hong, J.; Li, J.; Wang, P.; Zou, Z. Catalytic reduction of NO $\mathrm{N}_{\mathrm{x}}$ by CO over a Ni-Ga based oxide catalyst. J. Mater. Chem. A 2015, 3, 15133-15140. [CrossRef]

52. Lónyi, F.; Solt, H.E.; Pászti, Z.; Valyon, J. Mechanism of NO-SCR by Methane over Co, H-ZSM-5 and Co,H-mordenite Catalysts. Appl. Catal. B Environ. 2014, 150-151, 218-229. [CrossRef]

53. Song, I.; Lee, H.; Kim, D.H. Rotation-Assisted Hydrothermal Synthesis of Thermally Stable Multiwalled Titanate Nanotubes and Their Application to Selective Catalytic Reduction of $\mathrm{NO}$ with $\mathrm{NH}_{3}$. ACS Appl. Mater. Interfaces 2018, 10, 42249-42257. [CrossRef]

54. Dorado, F.; Lucas, A.; Garcia, P.B.; Romero, A.; Valverde, J.L.; Asencio, I. SCR of NO by Propene on Monometallic (Co or Ni) and Bimetallic (Co/Ag or Ni/Ag) Mordenite-Based Catalysts. Ind. Eng. Chem. Res. 2005, 44, 8988-8996. [CrossRef]

55. Yang, T.T.; Bi, H.T.; Cheng, X. Effects of $\mathrm{O}_{2}, \mathrm{CO}_{2}$ and $\mathrm{H}_{2} \mathrm{O}$ on $\mathrm{NO}_{\mathrm{x}}$ adsorption and selective catalytic reduction over Fe/ZSM-5. Appl. Catal. B Environ. 2011, 102, 163-171. [CrossRef] 
56. Jiang, J.; Zheng, R.; Jia, Y.; Guo, L.; Huang, M.; Hu, J.; Xi, Y. Investigation of $\mathrm{SO}_{2}$ and $\mathrm{H}_{2} \mathrm{O}$ poisoning over Cu-HPMo/TiO 2 catalyst for Low temperature SCR: An experimental and DFT study. Mol. Catal. 2020, 493, 111044. [CrossRef]

57. Liu, G.; Zhang, W.; He, P.; Guan, S.; Yuan, B.; Li, R.; Sun, Y.; Shen, D. $\mathrm{H}_{2} \mathrm{O}$ and/or $\mathrm{SO}_{2}$ Tolerance of Cu-Mn/SAPO-34 Catalyst for NO Reduction with NH3 at Low Temperature. Catalysts 2019, 9, 289. [CrossRef]

58. Lai, J.-K.; Wachs, I.E. A Perspective on the Selective Catalytic Reduction (SCR) of $\mathrm{NO}$ with $\mathrm{NH}_{3}$ by Supported $\mathrm{V}_{2} \mathrm{O}_{5}-\mathrm{WO}_{3} / \mathrm{TiO}_{2}$ Catalysts. ACS Catal. 2018, 8, 6537-6551. [CrossRef]

59. Nascimento, J.P.S.; Oton, L.F.; Oliveira, A.C.; Rodríguez-Aguado, E.; Rodríguez-Castellón, E.; Araujo, R.S.; Souza, M.S.; Lang, R. Selective Catalytic Reduction of $\mathrm{NO}_{x}$ by $\mathrm{CO}$ over Doubly Promoted MeMo/ $\mathrm{Nb}_{2} \mathrm{O}_{5}$ Catalysts $(\mathrm{Me}=\mathrm{Pt}, \mathrm{Ni}$, or Co). Catalysts 2020, 10, 1048. [CrossRef]

60. Zhang, S.; Zhang, B.; Liu, B.; Sun, S. A review of Mn-containing oxide catalysts for low temperature selective catalytic reduction of $\mathrm{NO}_{x}$ with $\mathrm{NH}_{3}$ : Reaction mechanism and catalyst deactivation. RSC Adv. 2017, 7, 26226-26242. [CrossRef]

61. Souza, M.S.; Araújo, R.S.; Oliveira, A.C. Optimizing reaction conditions and experimental studies of selective catalytic reduction of NO by CO over supported SBA-15 catalyst. Environ. Sci. Pollut. Res. 2020, 27, 30649-30660. [CrossRef] [PubMed]

62. Kim, S.-J.; Yun, Y.-U.; Oh, H.-J.; Hong, S.H.; Roberts, C.A.; Routray, K.; Wachs, I.E. Characterization of Hydrothermally Prepared Titanate Nanotube Powders by Ambient and In Situ Raman Spectroscopy. J. Phys. Chem. Lett. 2010, 1, 130-135. [CrossRef]

63. Wan, Y.; Zhao, W.; Tang, Y.; Li, L.; Wang, H.; Cui, Y.; Gu, J.; Li, Y.; Shi, J. Review Ni-Mn bi-metal oxide catalysts for the low temperature SCR removal of $\mathrm{NO}$ with $\mathrm{NH}_{3}$. Appl. Catal. B Environ. 2014, 148-149, 114-122. [CrossRef] 